\title{
Effects of Colloidal Silica Grouting on Geotechnical Properties of Liquefiable Soils: A Review
}

\author{
Giovanni Ciardi *(1), Giovanni Vannucchi and Claudia Madiai \\ Department of Civil and Environmental Engineering, University of Florence, Via di S. Marta 3, \\ 50139 Florence, Italy; giovanni.vannucchi@unifi.it (G.V.); claudia.madiai@unifi.it (C.M.) \\ * Correspondence: giovanni.ciardi@unifi.it
}

Citation: Ciardi, G.; Vannucchi, G.; Madiai, C. Effects of Colloidal Silica Grouting on Geotechnical Properties of Liquefiable Soils: A Review.

Geotechnics 2021, 1, 460-491. https:// doi.org/10.3390/geotechnics1020022

Academic Editor: George Mylonakis

Received: 20 October 2021

Accepted: 26 November 2021

Published: 30 November 2021

Publisher's Note: MDPI stays neutral with regard to jurisdictional claims in published maps and institutional affiliations.

Copyright: (c) 2021 by the authors. Licensee MDPI, Basel, Switzerland. This article is an open access article distributed under the terms and conditions of the Creative Commons Attribution (CC BY) license (https:// creativecommons.org/licenses/by/ $4.0 /)$.

\begin{abstract}
Colloidal silica (CS) is a kind of nanomaterial used in soil/rock grouting techniques in different branches of civil engineering. Many studies have recently been performed to investigate the potential of CS in improving the mechanical behavior of cohesionless soils and mitigating the risk of seismic liquefaction in urbanized areas. CS grout is chemically and biologically inert and, when injected into a subsoil, it can form a silica gel and stabilize the desired soil layer, thus representing an attractive, environmentally friendly alternative to standard chemical grouting techniques. This paper firstly describes the characteristics of CS grout, the gelation process and the main features of the behavior of the pure gelled material. The grout delivery mechanisms through porous media are then explained, pointing out the crucial issues for practical application of CS grouting. All the grouting-induced effects on the soil behavior, which have been investigated by laboratory tests on small-sized soil elements, are reviewed, including the modifications to soil strength and stiffness under both static and seismic loading conditions, to soil compressibility and hydraulic conductivity. Published results from physical model tests and in situ applications are also presented. Finally, some aspects related to the mechanism of soil improvement are discussed. A critical discussion of each topic is presented, drawing particular attention to the controversial or not yet fully examined aspects to which future research on colloidal silica grouting should be directed.
\end{abstract}

Keywords: colloidal silica; liquefaction; nanomaterials; chemical grouting; soil stabilization; review study

\section{Introduction}

In the present era of demographic expansion, the need for buildings and infrastructures is growing exponentially and, as a result, the demand for land is increasing very quickly. However, especially in some areas of the world, the scarcity or inadequacy of available soils for urban development often pose serious challenges on how to use them in a sustainable way to meet the needs required by society.

Consequently, ground improvement measures are increasingly being carried out to make the soil suitable for construction or to increase the safety of existing structures and other constructed facilities. A variety of soil improvement techniques have been developed over the past decades [1,2], and most of them are still being currently applied [3]. Among the existing techniques, permeation grouting is frequently used in geotechnical engineering practice to fill the soil voids: one of the most established chemical grouting techniques, it involves the injection under low pressure of a low-viscosity liquid by means of grouting pipes specially installed into the subsoil. The liquid permeates the soil, and it hardens over time, increasing the soil strength and creating a stiffer and less permeable material. Cohesionless soils, like clean sands or sand with low fines content, are best suited for this method. In chemical grouting, cement, silicates, acrylate, methacrylate, polyurethane, epoxy are the most traditional and commonly used stabilizing agents. The uncontrolled homogeneity of the grouting treatment, as well as any disturbance induced by the injection 
under pressure nearby existing structures, pipes and other constructed facilities, may affect the suitability of the use of some traditional types of grouts in urbanized areas. According to DeJong et al. [4], the poor-quality control resulting from common grouting procedures forces to an overestimated design, with consequences regarding environmental impact and economic costs. Therefore, sustainable alternatives to the use of traditional types of grouts are currently being investigated by researchers all over the world.

The recent steep growth of nanotechnology has led to a significant development of nanomaterials that could be successfully used in grouting practice with minimal drawbacks. According to the European Commission [5], a nanomaterial can be defined as "a natural, incidental or manufactured material containing particles, in an unbound state or as an aggregate or as an agglomerate and where, for $50 \%$ or more of the particles in the number size distribution, one or more external dimensions is in the size range 1-100 $\mathrm{nm}^{\prime \prime}$. According to Huang and Wang [6], the ratio of cost over performance of nanomaterials for soil improvement is better than that of traditional grouts, such as cement, sodium silicate, epoxy or acrylate. When this ratio was not too different, the environmental friendliness and the disturbance induced in the surrounding ground is in favor of nanomaterials.

In the field of geotechnical engineering, colloidal silica, bentonite, laponite and carbon nanotube are nanomaterials that have been recently applied to soil improvement [6]. Nanomaterials can be properly added to different kinds of soil to modify and improve some physical/mechanical properties of the natural material [6-9]. Significant changes in plasticity characteristics and hydraulic conductivity are induced in cohesive soils by the addition of nano-clay [10-12], and a significant decrease in the hydraulic conductivity can be achieved in sandy soils by grouting them with nano-silica solutions $[13,14]$. Nano-silica grout treatments can be used for soil remediation, e.g., to remove contaminants [15] or to form impervious barriers $[13,16,17]$, or in tunneling industry to prevent piping and to prevent water leaking through cracks $[18,19]$. Recently, the use of innovative nanomaterials has also been extensively investigated for the purpose of earthquake risk reduction. In view of possible applications for mitigation of seismic liquefaction hazard, a great number of studies has focused on analyzing the performance, under cyclic loading conditions, of sandy soils treated by nanomaterials such as bentonite, laponite and colloidal silica. The use of bentonite and laponite has proved effective in improving the behavior of sandy soils under cyclic loading [20-22] and a significant improvement of the cyclic liquefaction resistance has been observed in sandy soils treated with nano-silica solutions (e.g., [23-25]). This type of treatments can be listed among the recent innovative remediation methods against liquefaction [26,27], which also include the adoption of specific microbial-driven processes [28-30], the inducing of partial saturation [31-33], the recycling of waste materials, such as tire scraps $[34,35]$. Due to their environmental and economic sustainability, these innovative techniques may represent an alternative to other more conventional soil improvement methods that are commonly used to mitigate seismic liquefaction hazards (e.g., vibro-compaction, blasting, drainage) [36].

Among the above-mentioned innovative techniques for the improvement of liquefiable soils, this paper deals with colloidal silica (CS) grouting, which involves injecting a lowviscosity, time-hardening, non-pollutant, chemically and biologically inert solution into the soil voids [6,23]. Although the CS grouting technique had already been used for many years in different fields of civil engineering, the earliest studies on the use of CS grout for liquefaction risk mitigation date back to the beginning of this century (e.g., [23,37-39]). Since then, a huge number of works dealing with this topic have been published. Most of them refer to experimental studies on small-size soil elements, while others refer to physical models and field tests. These studies have allowed rapid development with non-stop updates of knowledge on CS grouting, as recently highlighted in $[40,41]$.

The aim of this paper is to provide an overview, as complete as possible and combined with a critical analysis of the results presented in the reviewed studies, of the existing literature on the use of colloidal silica grouting for the stabilization of cohesionless soils with emphasis on the mitigation of seismic liquefaction. The main goals can be summarized 
as follows: (i) to provide the reader with the most recent state of knowledge on the use of CS grouting in cohesionless soil; (ii) to give a comprehensive review of benefits/drawbacks of this non-conventional soil stabilization method; (iii) to give a critical summary of the most significant results obtained from laboratory investigations, in situ testing and modeling approaches on soil stabilized by CS grout.

After presenting a literature overview on the use of CS grouting followed by the description of the CS properties, the mechanisms of grout transportation are described pointing out the crucial problems for practical implementation of CS grouting. The discussion around the experimental results on CS grouted materials is then presented, examining all different aspects of the behavior of treated soil. After reviewing in field applications of CS grouting for liquefaction mitigation, the mechanism of soil improvement and the proposed modeling approaches are also discussed. Special attention is paid to those aspects (i.e., soil compressibility) that have been less investigated in previous studies, despite their importance for the possible side effects of the CS treatment.

\section{Overview of Literature on the Use of Colloidal Silica Grouting}

Since the beginning of this century, engineers have become increasingly familiar with the best practical use of treatments by nanomaterials, and among them numerous studies have been published highlighting benefits and drawbacks of colloidal silica (CS) grouting. Although CS grouting could potentially be applied in several fields of civil and environmental engineering (e.g., in tunneling construction [19], to prevent piping and to prevent water leaking through cracks, or in environmental interventions [17] to remove contaminants or to form impervious barriers; in the petroleum industry [42], to reduce the rock permeability to water and gases), most of the published studies analyze the behavior of grouted soil under cyclic loading, with the main purpose of investigating the effectiveness of the treatment for seismic liquefaction mitigation. The interest in this specific field of application has known a great impulse starting from the concept of passive site remediation [43], according to which a soil layer can be stabilized by permeating CS grout under low injection pressure, or by exploiting ground-water flow, without causing disturbance to the overlying existing structures (Figure 1).

A colloidal silica grout is a low-viscosity and harmless solution which increases its viscosity over time forming a colloidal silica gel [44-46]. The resulting colloidal silica gel act as a filler/binder among soil particles, stabilizing the material [14,24,47-50]. Initially and for some time, depending on a rheological behavior that can be controlled and designed, the CS grout can be moved through highly permeable media, like sands, just by natural or groundwater flow supplied without the need of high injection pressures, allowing minimization of negative side-effects on the surrounding environment $[23,51,52]$. Therefore, the use of colloidal silica grouting would be particularly favorable where other standard ground improvement techniques (e.g., densification, drains installation, etc.) could not be safely applied $[37,53,54]$.

To date, most of the different aspects concerning the colloidal silica grout properties and the effects of grouting on the behavior of cohesionless and sandy soils, as well as the entire grouting process, have been investigated. The published literature includes studies on the grout properties and on the management of its rheology, on the grout delivery mechanism, and on the effects of the colloidal silica grouting on physical soil properties and soil mechanical behavior. Excluding studies which only analyzed the behavior of pure colloidal silica grout [46,55-59], most of the published studies on colloidal silica grouting deal with laboratory investigations on grouted cohesionless materials. These studies differ in the materials used (kind of grout and soil), in the specimens' formation methods and in the kind of performed laboratory tests, so that it is often not immediately possible to compare their results. As this review comes from a critical evaluation of existing published data, some themes are discussed more in-depth than others, reflecting the same tendency of scientific literature. 
The response of colloidal silica grouted liquefiable material to dynamic and cyclic loading has been widely investigated by many authors. Published data generally agree that the liquefaction resistance of grouted soil improves due to soil grouting, and that the level of improvement is directly related: (i) to the amount of silica particles diluted in the stabilizing grout; (ii) to the time between the end of the gelation process and the beginning of testing (known as curing time), increasing as both these factors increase [14,23-25,37-39,47-50,60-70]. The same findings apply for grouted material subjected to static loading conditions $[14,37,48-50,60,61,63-65,67,69-76]$. The behavior of grouted soil under dynamic loading at low-medium strain levels has been much less analyzed [77-79]. According to published data, the shear modulus of grouted sand is expected to be greater than that of untreated material; however, there is still some disagreement on how much the damping ratio is affected by grouting.

On the contrary, it is well established that grouting leads to a dramatic reduction in the soil hydraulic conductivity. This decrease can be of several magnitudes, and the more the silica concentration in the grout, the more the expected permeability decreases, up to values typical of clay $[13,14,17,66,72]$. Finally, the effects of grouting on the soil compressibility have been scarcely investigated, even though this knowledge is fundamental for practical applications (the compressibility of soil would influence the settlements of structures and infrastructures in the area of intervention) $[14,37,67,70-72]$. Most of the results show that the treated soil is more compressible than the untreated one, even though a strict comparison among these data is not possible due to the differences in testing conditions.

The mechanism of grout-delivery has been investigated in several studies by largescale grouting laboratory tests [51,52,80-82]. These studies agree that the most important factors affecting the grout transportation are the increase in grout viscosity, the injection pressure, the grout sinking. Field-test and full-scale applications of colloidal silica grouting are documented, representing, however, a very small part of the published literature $[83,84]$. These studies also contain limited information about in situ tests (e.g., the cone penetration test, CPT) used to evaluate the performance of colloidal silica grouting. Lastly, few studies discuss the constitutive modelling approach to represent the behavior of cohesionless soils stabilized by colloidal silica grouting $[60,85]$; in these studies, an effort in modeling this behavior was made by adapting existing constitutive models to reproduce some experimental data from grouted soil.

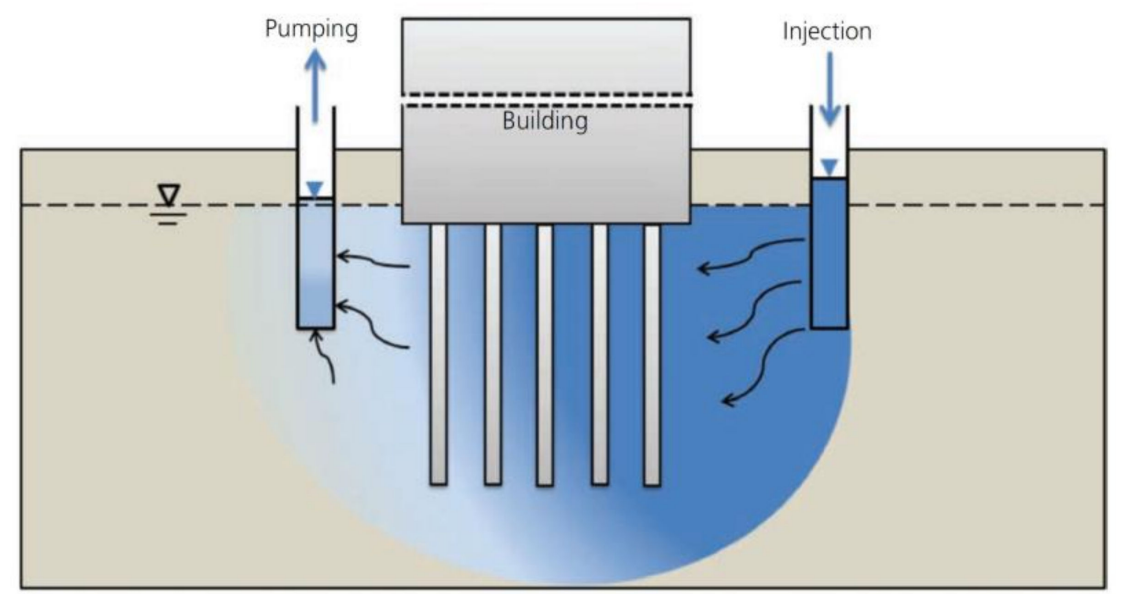

Figure 1. Scheme of passive site remediation by colloidal silica grouting [85].

\section{Colloidal Silica: An Overview}

\subsection{Main Characteristics and Gelation Process}

A colloidal silica (CS) sol can be defined as a stable dispersion of silica $\left(\mathrm{SiO}_{2}\right)$ solids of colloidal size (ranging from 1 up to $100 \mathrm{~nm}$ ) into a liquid phase [44]. It is obtained from saturated solutions of silicic acid and it is a clear, harmless, and low viscosity fluid that is commercially available with different (given) silica contents. Colloidal silica is not 
pollutant, it is chemically and biologically inert $[6,44,45,86]$, and it has excellent durability properties [50,87]. If diluted to $5 \%$ CS particles by weight, the material cost could be comparable to that of microfine cement, with a viscosity $(1.5-2 \mathrm{cP})$ comparable to that of water $\left(1 \mathrm{cP}\right.$ at $\left.20^{\circ} \mathrm{C}\right)$ [25].

The colloidal silica gel originates from the hardening process of a given CS dispersion. Silica particles agglomerate, forming a network of silica clusters connected by siloxane ( $\mathrm{Si}-\mathrm{O}-\mathrm{Si}$ ) bonds. The gelation process depends on the different factors affecting the interaction among silica nanoparticles, namely the silica content, the ion concentration (ionic strength), the temperature, the particles' size and the $\mathrm{pH}$ in the CS dispersion [23,46,57-59]. The time between the start and the end of the hardening process (known as gel time) decreases as silica content, ionic strength and temperature increase, while it increases as particles' size increases; the minimum gel time is achieved for $\mathrm{pH}$ in the range 5-6 $[13,43,57,80,88-90]$. Figure 2 shows the effects of the temperature (T) on the viscosity $(\mu)$ increase in a CS grout, over time $(t)$.

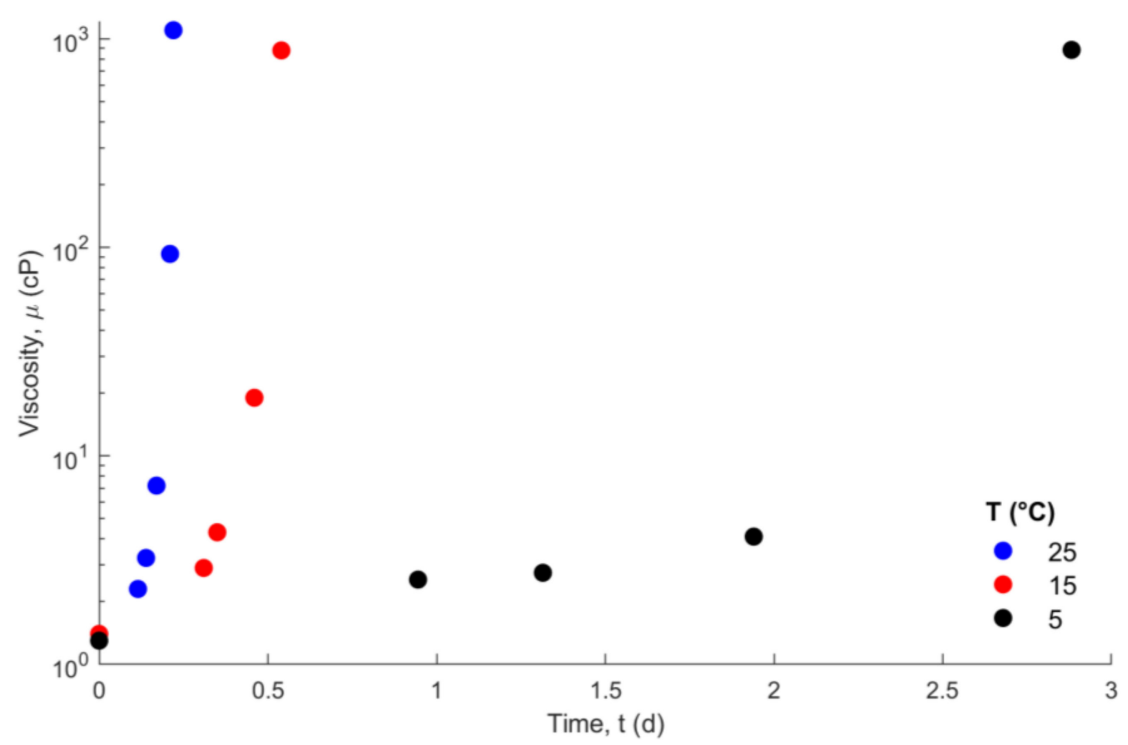

Figure 2. Viscosity against time for a $10 \% \mathrm{CS}$ solution $(\mathrm{NaCl}$ normality $=0.1 \mathrm{~N}, \mathrm{pH}=6.0)$ : effects of temperature (mod. from [46]).

The gel time can be varied from minutes to days $[13,46,52,57,63,80]$. The control and prediction of the gelation process are crucial issues for practical application of CS grouting, because the gel time should be long enough to avoid early gelation, so that the grout can be delivered where designed [83], but it should also be as short as possible to avoid grout dilution and sedimentation [81,84]. Visual observation of the formed gel $[13,72]$ or viscosity measurements $[25,46,52]$ are usually performed in the laboratory to define the gel time for a given CS grout, the latter often indicating the mixture of a CS dispersion with an activator, whose job is to promote the gelation process. Using an electrolyte (i.e., a salt-based solution, such as a $\mathrm{NaCl}, \mathrm{KCl}$ or $\mathrm{CaCl}_{2}$ solution) as an activator is considered the simplest method for the gel time control [81]. Figure 3 shows five different CS mixtures $(100 \mathrm{~mL})$ prepared at the same time with the same initial silica content (5\% by weight) and different amounts of activator, ranging from $30 \%$ to $70 \%$ (by volume). The picture was taken $\approx 10 \mathrm{~min}$ after mixing. As can be seen, as the percentage of activator increases, the solution changes from clear ( $30 \%$, still liquid state) to matte ( $70 \%$, gel state). It should be emphasized that, since the commercial colloidal silica solutions have generally different characteristics (i.e., particles' mean size), the same value of CS content may not mean the same thing in different research studies and this should be considered when comparing their results. 


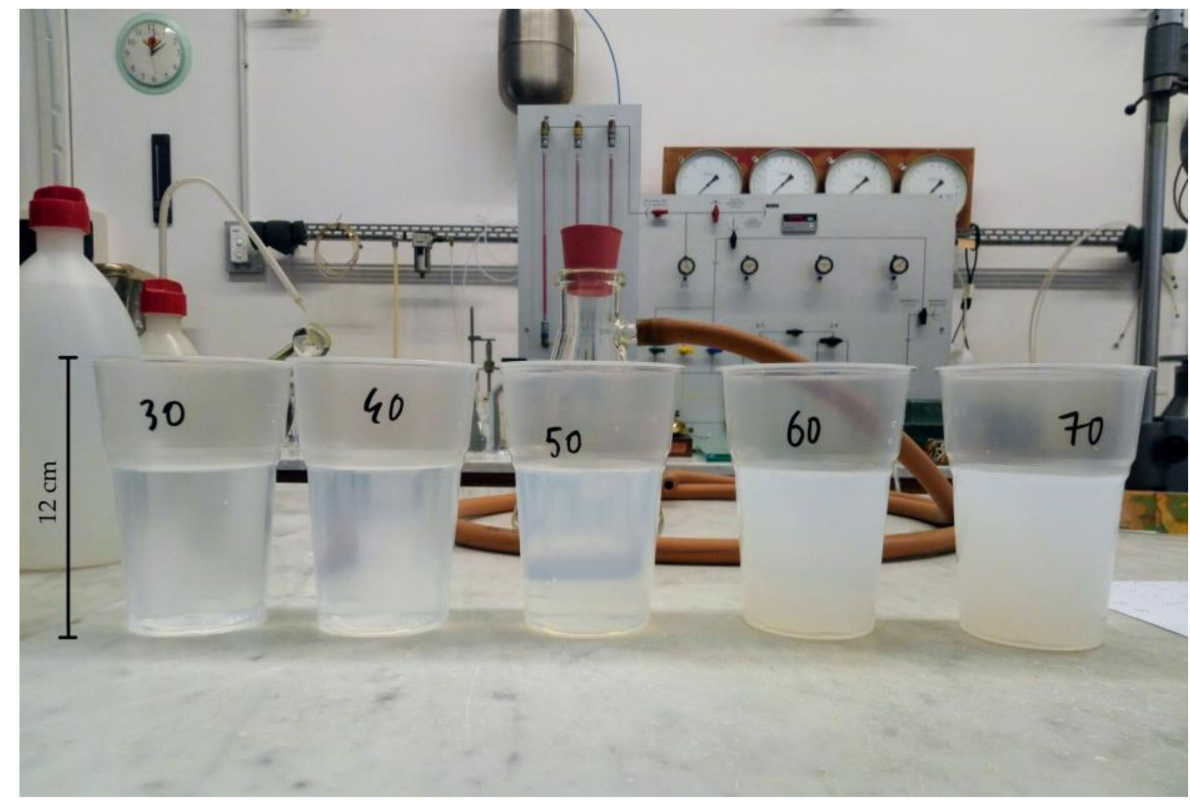

Figure 3. Colloidal silica mixtures ( $5 \%$ CS content) prepared at different ratios of activator to the volume of grout, ranging from $30 \%$ to $70 \%$ ( $\approx 10$ min after mixing).

\subsection{Pure Silica Gel Properties}

The properties of the pure CS gel (i.e., not combined with soil) for engineering purposes have been scarcely presented and discussed in scientific literature. The strength of the gel structure is strongly related to the amount and strength of silica agglomerates developed during the gelation process. The gel strength increases over time because of the progressive formation of siloxane bonds, while the electrolyte concentration in the grout affects the gel time, but not the strength of the resulting gel pattern [59], which is in turn affected by the amount of silica solids and by the type of the activator [58].

Experimental evidence proves that the strength of the pure gel is generally low, (typically few kilopascals after few days from specimen preparation, up to a few dozen as aging increases); in addition to the silica content, strength is affected by the relative humidity and increases, for a certain test type, with samples' age. Liao et al. [38] measured a gel strength of $6 \mathrm{kPa}$ after $7 \mathrm{~d}$, increasing up to $18 \mathrm{kPa}$ after $28 \mathrm{~d}$, in vane shear tests. Axelsson [55] performed fall cone and compressive strength tests on rectangular samples $40 \times 40 \times 160 \mathrm{~mm}$ (height $\times$ width $\times$ length). The CS silica sol ( $35 \%$ CS by weight) was mixed with accelerator at the 8:1 weight ratio. Tests were performed at $8{ }^{\circ} \mathrm{C}$ with relative humidity $75 \%, 95 \%, 100 \%$. It was found that: (i) the strength of silica gel increased over time without having reached an apparent ultimate value after 6 months; (ii) the strength increase was faster at low humidity; (iii) the friction angle, in the Mohr-Coulomb failure model, increased from $\approx 20^{\circ}$ to $\approx 50^{\circ}$ after 6 months.

The CS liquid solution, apparently irrespective of CS content, is more compressible than water [66], and the gelled material is compressible [91]; this may explain why the pore pressure build-up is delayed in treated specimens subjected to cyclic loading (Section 5.1.1). In detail, Towhata [91] showed results from an unconfined compressive strength test performed on a $6.5 \%$ CS content gel specimen $(47 / 70 \mathrm{~mm}$ diameter/height, tested after $30 \mathrm{~d}$ curing in water), measuring both axial and radial strains. It was shown that the sample collapsed showing brittle behavior and strain softening, with peak deviatoric stress slightly $>5 \mathrm{kPa}$, and that the calculated Poisson's ratio was $\approx 0.3$ for gelled material, thus implying a volume compressibility of the gelled mixtures greater than that of water. Vranna and Tika [66] evaluated the compressibility of CS solutions before the gelation (CS contents $6 \%, 10 \%$ ) measured using a pressure and volume controller, in the isotropic stress range 100-300 $\mathrm{kPa}$. They showed that the compressibility of CS was 14-33 (under a stress of $100 \mathrm{kPa}$ ) and 12-18 (under a stress of $300 \mathrm{kPa}$ ) times greater than that of distilled 
and deaired water, and that the CS content did not have effects on the compressibility of CS. Similar results have also been recently shown in Vranna and Tika [68].

When subjected to confined 1D-compression tests, gelled samples exhibit significant strain depending on samples' age (Figure 4), gel time and curing environment. Butrón et al. [56] performed unconsolidated and consolidated undrained triaxial, unconfined compressive strength and oedometer tests on samples cured in different storage environment (temperature, relative humidity, chemical surrounding) and tested over a period of 5 months; $35 \%$ silica sol was mixed with accelerator at 8:1 weight ratio. They found that, given a combination of relative humidity and temperature, the shear stress in unconfined compressive strength tests increased with samples' age. Furthermore, specimens tested within 13 days after mixing exhibited a strain-hardening behavior, while samples tested after $29 \mathrm{~d}$ and $69 \mathrm{~d}$ showed a peak shear stress (strain-softening) in the range $27-33 \mathrm{kPa}$ from consolidated undrained triaxial tests (effective consolidation stresses around $10 \mathrm{kPa}$ and $20 \mathrm{kPa}$ for radial and axial stress, respectively). Up to $\approx 30 \%$ strain was measured $1 \mathrm{~d}$ after mixing from oedometer tests in the stress range $0-100 \mathrm{kPa}$, and strain generally decreased, given a stress level, with samples' age. From oedometer tests, they obtained hydraulic conductivity values in the range $10^{-10}$ to $10^{-11} \mathrm{~m} / \mathrm{s}$. These values, typical of clays, result from water flowing through small pore spaces randomly formed by particles aggregates [58].

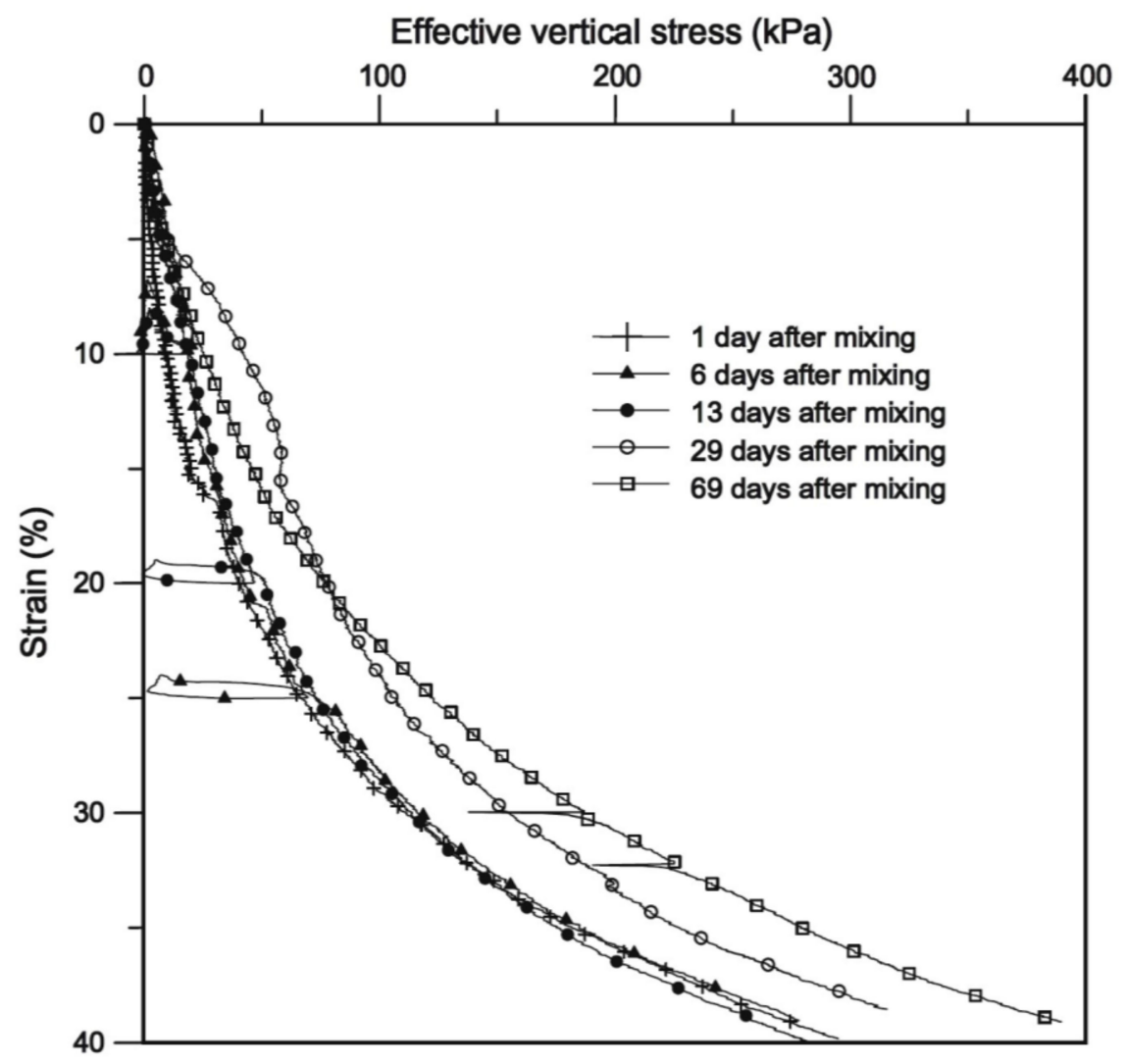

Figure 4. Oedometer test results on silica gel samples kept underwater at $8{ }^{\circ} \mathrm{C}$ with unloadingreloading paths ([56] with permission).

Wong et al. [72] performed oedometer tests on pure CS gel samples $(75 / 20 \mathrm{~mm}$ diameter/height, $1 \mathrm{~h}$ or $5 \mathrm{~h}$ gel times; cured under water or at $90 \%$ relative humidity (1-4 weeks); CS content $34 \%$, vertical stress up to $1000 \mathrm{kPa}$ ). All samples, irrespective of curing conditions, gel and curing time, exhibited significant void ratio decrease during loading. Samples cured for 4 and 8 weeks showed a stiffer response at low vertical stress levels than samples cured for 1 and 2 weeks while, at effective vertical stresses greater than about $25 \mathrm{kPa}$, the slope of the compression curve was similar for all samples. 
In conclusion, the experimental results from existing research on the behavior of CS solution and pure gel point out some fundamental aspects: (i) CS solution and gel are more compressible than fresh water; (ii) the strength of CS gel increases with time, and it is affected by environmental conditions such as relative humidity and temperature; (iii) CS gel has hydraulic conductivity values typical of clays.

\section{Transport of Colloidal Silica Grout through Porous Media}

A key aspect for practical application of CS grouting is the permeation mechanism of the stabilizing mixtures into targeted soil layers. The groutability of materials depends on the grout viscosity and on the hydraulic conductivity and grain size distribution of the permeated medium. Soils with hydraulic conductivity in the range $10^{-3}-10^{-5} \mathrm{~m} / \mathrm{s}$ and particle size in the range $0.05-2 \mathrm{~mm}$ are easily groutable by all commonly used chemical grouts [2]; liquefiable soils usually match both these criteria. Previous research dealing with colloids showed that they can move through sand aquifers [92-94]. Fujita and Kobayashi [95] evaluated the effects of the soil matrix, of the charge amounts of colloidal silica particles, and of the air-water interface on the transport of the colloid in saturated and unsaturated conditions, showing that the liquid transport significantly depends on $\mathrm{pH}$ (high mobility at higher $\mathrm{pH}$ ). Noll et al. [89] formed a permeability barrier ( $0.9 \mathrm{~m}$ wide) with CS in a $3.6 \mathrm{~m} \times 1.8 \mathrm{~m} \times 1.2 \mathrm{~m}$ sand box. The grout was delivered by means of three injection wells placed in the center of the container and three extraction wells located on two sides of the model. Noll et al. [96] used CS to stabilize a contaminated area, disposing one injection well surrounded by six extraction wells on a $6 \mathrm{~m}$ radius.

Gallagher and Finsterle [51] used delivered CS grout into a box model by means of injection and extraction wells under low hydraulic gradient. The model consisted of a $20 \mathrm{~cm}$ thick layer of loose sand (relative density, $\left.D_{\mathrm{r}}=40 \%\right)$ pluviated into a box $(76 \times 30 \mathrm{~cm}$, $26.5 \mathrm{~cm}$ height). Five PVC pipes were used to deliver the colloidal silica solution into the soil layer for $\approx 10 \mathrm{~h}$ (16.5 L of CS solution). Two additional pipes were used as extraction wells. The box model setup is shown in Figure 5 together with the red dyed CS grout progression after $3 \mathrm{~h}$. Curing time was set as $14 \mathrm{~d}$ once the grout delivery was completed. Specimens collected for unconfined compressive strength (UCS) tests after the box was dismantled showed UCS values in the range 16-61 kPa. The authors concluded that low-gradient injection and extraction wells could be successfully used for colloidal silica delivery.
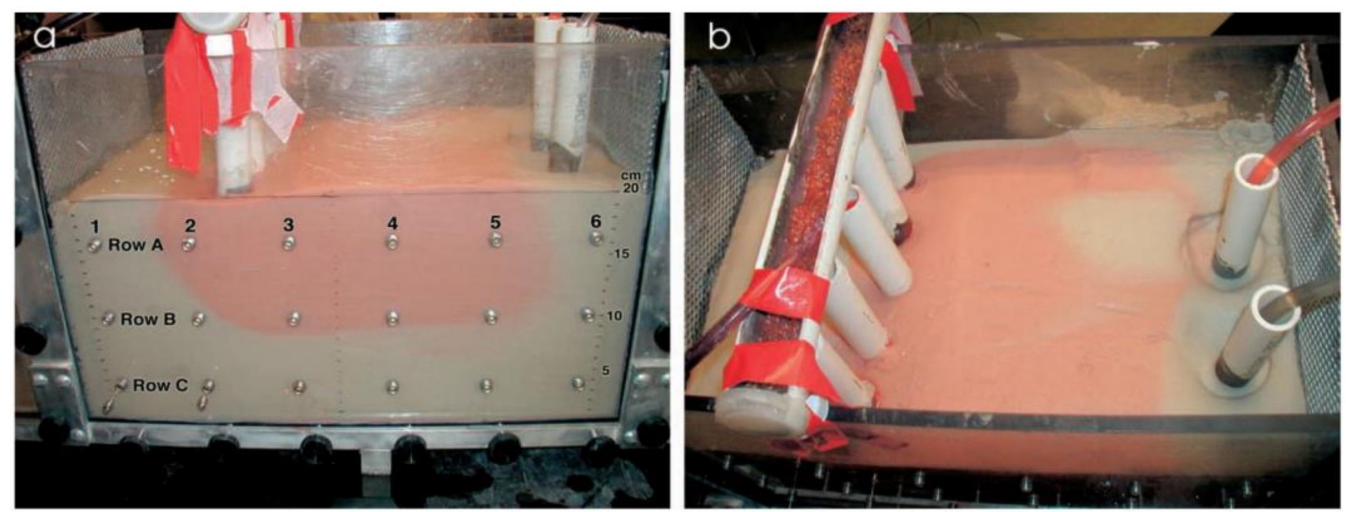

Figure 5. Setup of the box model experiment (grout flow is from left to right): side (a) and plan (b) view after $3 \mathrm{~h}$ CS progression ([51] with permission).

When dealing with CS grouting, together with the different density and viscosity of the grout and the water it displaces, the time-dependent gelation process must be considered. The gelation process leads to a progressive decrease in the hydraulic conductivity of the permeated media $[17,83,96]$, thus decreasing the rate of grout delivery. Gallagher and Lin [80] evaluated the permeation of colloidal silica grout by means of four soil columns $\left(D_{r}=40 \%\right)$ (Nevada 120 silica sand, mean particle diameter $\left.D_{50}=0.15 \mathrm{~mm}\right)$. They pointed 
out that the mixture's viscosity had the greatest influence on the grout travel time through the columns: once this viscosity approached $3.6 \mathrm{cP}$ the flow rate was greatly reduced. In a subsequent study, Gallagher and Lin [52] performed several column tests (0.9 m-length) on loose sand or graded silty sand specimens $\left(\mathrm{D}_{\mathrm{r}}=40 \%\right)$ permeated by CS grout under low hydraulic gradients $(0.04,0.09,0.18)$. The authors showed that the CS solution could successfully permeate the soil columns. For a viscosity value of $\approx 4 \mathrm{cP}$, the grout flow inside the columns essentially stopped. It was concluded that hydraulic gradients (i.e., injection pressures) must be appropriately chosen in accordance with the distance the grout has to cover, and by considering that the initial hydraulic conductivity of the medium decreased as the grout started gelling in the pores. Bolisetti et al. [82] analyzed the grout injection process (40\% CS grout mixed with $\mathrm{NaCl}$ solution (10\% by weight) at a $4: 1$ weight ratio) and the grout flow in sand columns (fine sand with $\mathrm{D}_{50}=0.2 \mathrm{~mm}$ and hydraulic conductivity in the range $2.7-3.3 \cdot 10^{-4} \mathrm{~m} / \mathrm{s}$ ), confirming that the increase in the grout viscosity during gelation significantly affected its permeation; sinking of silica due to the grout density should also be considered because the CS particles of the grout may sediment where not required.

Hamderi and Gallagher [97] evaluated injection and extraction rates, and optimum wells disposal, for in-field colloidal silica treatment by means of numerical analysis. The authors pointed out the importance of the extraction flow rate for horizontal colloidal silica delivery. They also found that a distance from the inlet to the outlet well between 2 and $4 \mathrm{~m}$ could provide the soil with enough improvement for the maximum simulated injectionextraction rates available. Conversely, when low injection/extraction rates were adopted, the problem of grout sinking may occur, suggesting properly estimation of the minimum flow rate when designing the treatment for a specific site. Hamderi and Gallagher [81] developed a pilot-scale facility to investigate the delivery mechanism of colloidal silica grout. Liquefiable sand $\left(\mathrm{D}_{\mathrm{r}}=22 \%\right.$, hydraulic conductivity $1.8 \times 10^{-3} \mathrm{~m} / \mathrm{s}$ ) was put into a large box facility $(243 \times 366 \mathrm{~cm}, 122 \mathrm{~cm}$ deep $)$ and treated by a colloidal silica grout transported by means of injection and extraction wells. Both low-rate (2) and high-rate (6) injection tests were performed. For low-rate tests, 6\% CS solution was used, and it was made to move at a flow rate of $65 \mathrm{~mL} / \mathrm{min} /$ well (total flow rate equal to $260 \mathrm{~mL} / \mathrm{min}$ ) for the first test; due to sinking problems during the grout delivery, the flow rate was doubled for the second test and the relative density of the sand was increased to $48 \%$. For high-rate tests, a 9\% CS by weight solution was used for just one test, while for the remaining part a tracer $\mathrm{NaCl}$ solution was used. At the end of the high-rate test with $\mathrm{CS}$ grout, the treated sand was left 25 days to cure before it was excavated. The injection rate for this test was set at $6800 \mathrm{~mL} / \mathrm{min} /$ well (approximately $50 \mathrm{kPa} /$ well). A $0.3 \mathrm{~m}$ deep horizontal surface was used for testing with a pocket penetrometer. Finally, 24 cylindrical samples were trimmed and subjected to unconfined compressive strength tests. The CS concentration resulting after the grout permeation was estimated from electrical conductivity measurements, and by relating pocket penetrometer and UCS measures on treated sand samples.

In addition to the viscosity increase, which may stop the delivery process and prevent the target location being reached, the grout sinking is a crucial issue in the CS grout treatment. It is governed by the difference between the density of the grout and that of the water it displaces [81,97-99] and, as a consequence, the grout could not be delivered to the target location with the required design properties. Hamderi and Gallagher [97] pointed out that the maximum practical injection distance for colloidal silica is in the range 2.5-4 m, to avoid sinking. Hamderi and Gallagher [81] observed on a physical model that sinking was much more significant when low injection rates were used instead of high injection rates for grout delivery. As stated by Weggel et al. [98], while the viscosity increase reduces the grout flow due to a decrease in hydraulic conductivity, the density of $\mathrm{CS}$, greater than that of the water it displaces, tends to increase its flow-rate. In numerical simulation of grout injection, Gallagher and Finsterle [51] took into account the different densities of water and stabilizer assuming that their volumes were additive. Moreover, they also used a relationship to describe the stabilizer viscosity increase and a mathematical 
power-law expression to calculate the time-dependent viscosity of the liquid phase, which they assumed consisted of water, stabilizer and dissolved air. Agapoulaki et al. [99], after performing 1D-flow tests on soil columns permeated by $10 \%$ CS solution, proposed an analytical tool based on a modified Darcy's law in order to predict the grout flow rate considering different densities of water and CS, and viscosity changes over time. Weggel et al. $[98,100]$ developed an analytical model to evaluate the rate at which the CS solution displaces the water while moving through a porous medium column (1D flow). The combined effects of density and viscosity difference between CS dispersion and water were taken into account, and the proposed model was validated by comparison with data on one-dimensional CS flow described in a previous work by Lin [101].

\section{Influence of Colloidal Silica Treatment on Soil Behavior-Laboratory Investigations}

Most of previous research studies dealing with CS grouting consist of laboratory studies. This section reviews the most significant results obtained by researchers from laboratory experimental activities on CS grouted soil. The behavior of treated material under dynamic and cyclic loading is discussed distinguishing between liquefaction-related problems and soil response up to medium-strain levels, followed by a discussion on the soil response under static loading conditions.

When performing laboratory tests on CS-treated soil, a crucial issue is represented by the specimen preparation method. Basically, two different methods have been extensively used in the literature. The first one consists of pluviating the dry sand directly into the liquid grout to achieve a desired initial relative density, waiting for the gel time and curing time to expire, and then moving the specimen into the testing apparatus. The second one consists of grout permeation through the specimen, which was previously prepared in standard ways (e.g., dry tamping, moist tamping, dry deposition, etc.) and possibly pre-saturated with deaired water. While the first method ensures good homogeneity, full gel saturation and reproducible laboratory results, it is not representative of field conditions (i.e., grout injection). On the other hand, despite being much more representative of field injection, the second one does not guarantee a homogeneous grout distribution.

Before going through details of tests and results collected from the literature, the role of back-pressure saturation in cyclic as well as monotonic triaxial tests needs to be discussed. The application of a back-pressure is usually performed as a standard procedure to dissolve air bubbles and to promote water saturation of the sample before the consolidation and shearing phases. For treated soil, most of the tests reported in older studies and in some recent ones were performed without prior water saturation $[14,23,63,66,68,69]$ to avoid disturbance to the gelled material. On the contrary, in other studies soil specimens were previously saturated $[48,64,70,71,74]$, in some cases using very high values of the backpressure (up to $700 \mathrm{kPa}$ ). When back-pressure saturation is not performed, pore pressure response is not measured during the shearing phase and test results are processed with reference to total stress, or assuming that mean total and effective stresses are practically identical [68]. Vranna et al. [68] showed the results from monotonic undrained triaxial tests on treated and untreated loose sand specimens subjected to different back-pressure values, pointing out that the magnitude of back-pressure had a strong influence on the stress-strain response of the material. Georgiannou et al. [71] showed that the results of drained monotonic triaxial tests were independent from the back-pressure magnitude, which was in the range $300-700 \mathrm{kPa}$. The same range of values was adopted by Triantafyllos et al. [74], who stated that increasing the back-pressure within this range does not produce damage to the gel since they observed that drained loading on similar stabilized samples gave reproducible results. Pavlopoulou and Georgiannou [70] obtained repeatable results from specimens that were back-pressure saturated in a standard way; they also stated that increasing the pore water pressure does not damage the gel, and that the treated sand response is controlled by the effective stresses; thus, measuring the pore water pressure response is required in laboratory tests on CS-treated sand. 


\subsection{Mechanical Behavior under Dynamic and Cyclic Loading Conditions}

\subsubsection{High Strain Levels and Liquefaction}

Huang and Wen [26] included CS grouting among the newly developed techniques against liquefaction. Mitigating the liquefaction effects by CS grouting has been the main goal of several studies since the beginning of this century (e.g., [23,38,39]). It is well established that seismic liquefaction arises due to the pore water pressure build-up developed in loose saturated sandy and silty soils with no plastic fines under cyclic loading conditions [36,102-105]. Reducing the pore water pressure development and bonding the grains are two effective ways to improve the soil behavior against liquefaction [106]. These effects can be successfully induced by CS grouting.

Undrained cyclic triaxial and cyclic simple shear tests have been extensively used by researchers, together with cyclic torsional shear tests. The compressibility of the pore gel poses the question whether the pore pressure response should have the same meaning in treated and untreated material [24]. Therefore, the definition of initial liquefaction as the condition at which the increase in pore pressure is equal to the initial effective confining pressure (pore pressure ratio $r_{u}=100 \%$ ) may not be fully satisfactory to identify failure (or a state of softening) in treated specimens. Thus, the achievement of a given value of strain (usually, but not as a rule, $5 \%$ double amplitude axial strain in cyclic triaxial or $7.5 \%$ double amplitude shear strain in cyclic simple shear tests) has been extensively used as a criterion to coherently define the state of failure condition for treated sand $[14,47,48,61,64,68,69]$.

As unanimously observed in the literature, regardless of tested materials and testing conditions (i.e., test type, adopted failure criterion, specimens' dimensions, formation method and relative density, soil characteristics, CS characteristics, etc.), the liquefaction resistance of treated material is higher than that of the untreated one, and increasing silica content usually leads to higher liquefaction and deformation resistance, both increasing as samples' age increases $[14,23,25,37,38,47,49,50,61,64,66,68-70,107]$. The axial strain is not symmetric about the zero strain axis (shifted towards the extension region) $[23,64,68-70]$.

Figure 6 shows the results, in terms of axial strain $\left(\varepsilon_{a}\right)$ versus number of loading cycles $\left(\mathrm{N}_{\mathrm{c}}\right)$, of cyclic triaxial tests performed on treated and untreated sand. Figure 6a shows the comparison between treated (CS content $2 \%$ ) and untreated (CS content $0 \%$ ) loose sand; Figure $6 \mathrm{~b}$ shows the comparison between treated loose sand (CS content $5 \%$ ) and dense untreated sand. The tests were performed without prior saturation and pore pressure measurements. As shown in Figure 6a, for a very similar Cyclic Stress Ratio (CSR) value, the treated sand specimen does not fail ( $5 \%$ double amplitude axial strain), while failure (the condition $r_{u}=100 \%$ is followed by the development of large strain) occurs after a few cycles for the untreated one. Figure $6 \mathrm{~b}$ shows that, for the same CSR, the treated sand specimen does not fail, despite it having a much lower relative density than the untreated dense sand specimen.

Figure 7 refers to the results of cyclic triaxial and simple shear tests with pore pressure measurements on treated and untreated loose sand. It shows the average trends of maximum pore pressure ratio against the ratio of number of loading cycles $\left(\mathrm{N}_{\mathrm{c}}\right)$ to the number of cycles at failure $\left(\mathrm{N}_{\mathrm{f}}\right)$. The loading path (triaxial or simple shear) does not have significant effect on the pore pressure development for the untreated sand while it markedly influences the response of treated material. In treated sand, the pore pressure developed faster in the triaxial test than in the simple shear test, and in both cases the pore pressure build-up was faster in grouted sand than for untreated sand. However, differently from untreated sand, the $r_{u}=1.0$ condition was not reached. A faster development of pore pressure in grouted sand was also reported by Porcino et al. [48] from undrained cyclic simple shear tests and by Pavlopoulou and Georgiannou [70] from undrained cyclic triaxial tests on loose and medium-dense treated sands; in the latter study, the authors also observed that the condition $r_{u}=1.0$, that could be reached either by treated and untreated sand, did not indicate the collapse in treated material. 

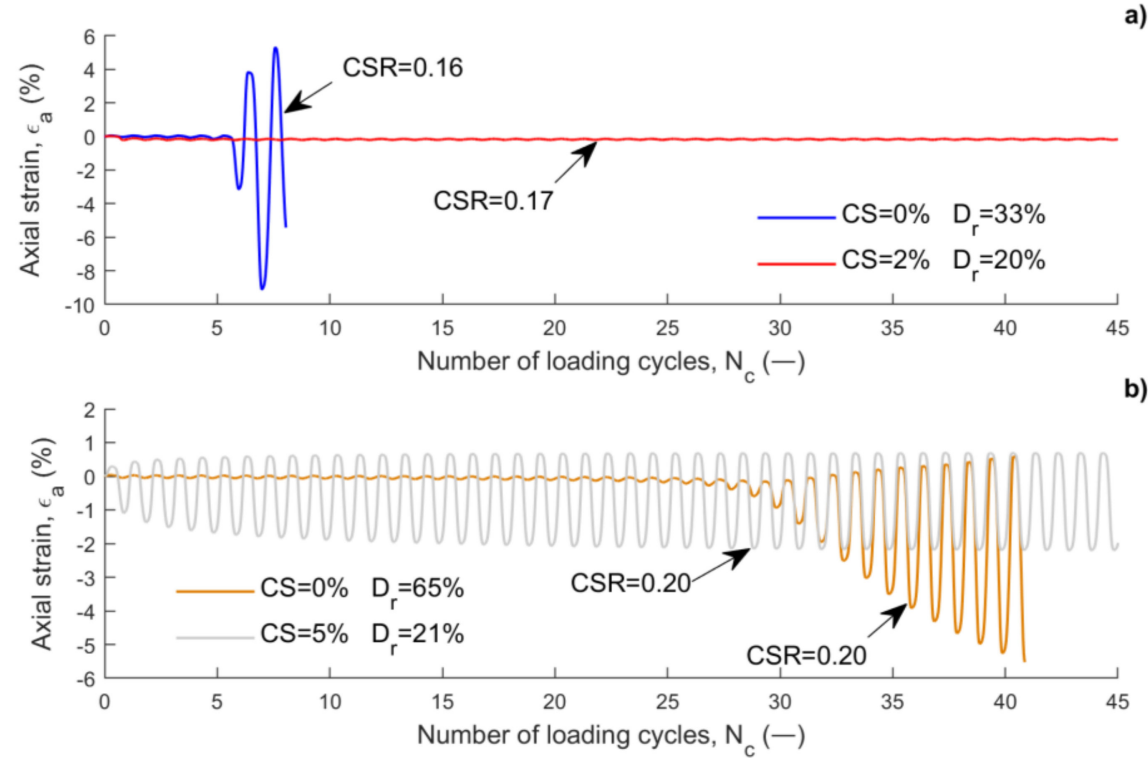

Figure 6. Axial strain versus number of loading cycles: (a) untreated and 2\% CS-treated specimens; (b) untreated and 5\% CS-treated specimens (mod. from [14]).

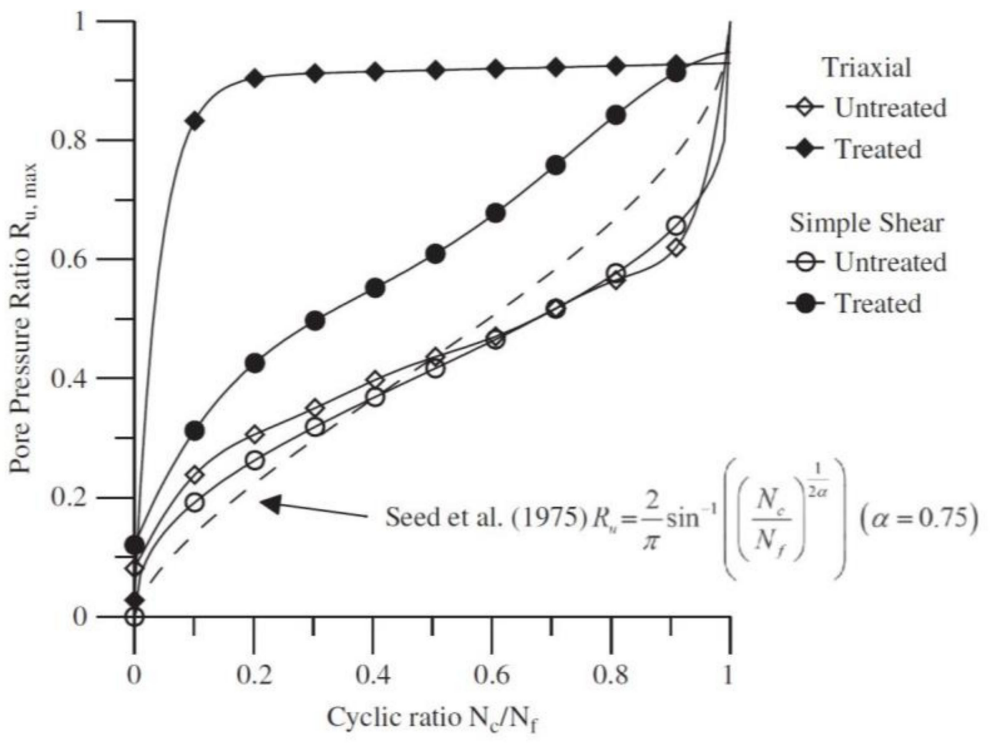

Figure 7. Non-dimensional pore pressure build-up for treated and untreated sand for different loading conditions ([64] with permission).

Conversely, Díaz-Rodríguez and Antonio-Izarraras [39] and Díaz-Rodríguez et al. [47] from results of cyclic simple shear tests, showed a delayed increase in pore pressure in the treated loose soil compared to the untreated one, with a slower rate of increase as the CS content increased. However, it should be noted that the initial vertical effective stress used by Porcino et al. [64] was significantly higher than that used in Díaz-Rodríguez and Antonio-Izarraras [39] and Díaz-Rodríguez et al. [47]; in addition, in the latter, the pore pressure was not directly measured, but it was obtained from the changes in vertical stresses that were required to keep a constant height of the specimen, and in Díaz-Rodríguez and Antonio-Izarraras [39] no details are given on how the pore pressure response was assessed.

By drawing the liquefaction resistance curves of treated and untreated materials in the number of cycles to failure-Cyclic Stress Ratio plane, it is therefore expected that the resistance curve of treated soil lays above that of the untreated sand. By way of example, Figure 8 shows typical liquefaction resistance curves of treated materials compared with the corresponding curves for the untreated sands, collected from different studies on 
CS-treated materials. CS grouting produces an increase in liquefaction resistance that can be related to the effect of particles densification [64]. Towhata and Kabashima [37] showed that the effect on loose Toyoura sand (relative density $D_{r}=40 \%$ ) of $4.5 \%$ CS content grout was equivalent to densification $\left(\mathrm{D}_{\mathrm{r}}\right.$ within $75.1 \%$ and $77.8 \%$ ) of untreated sand.

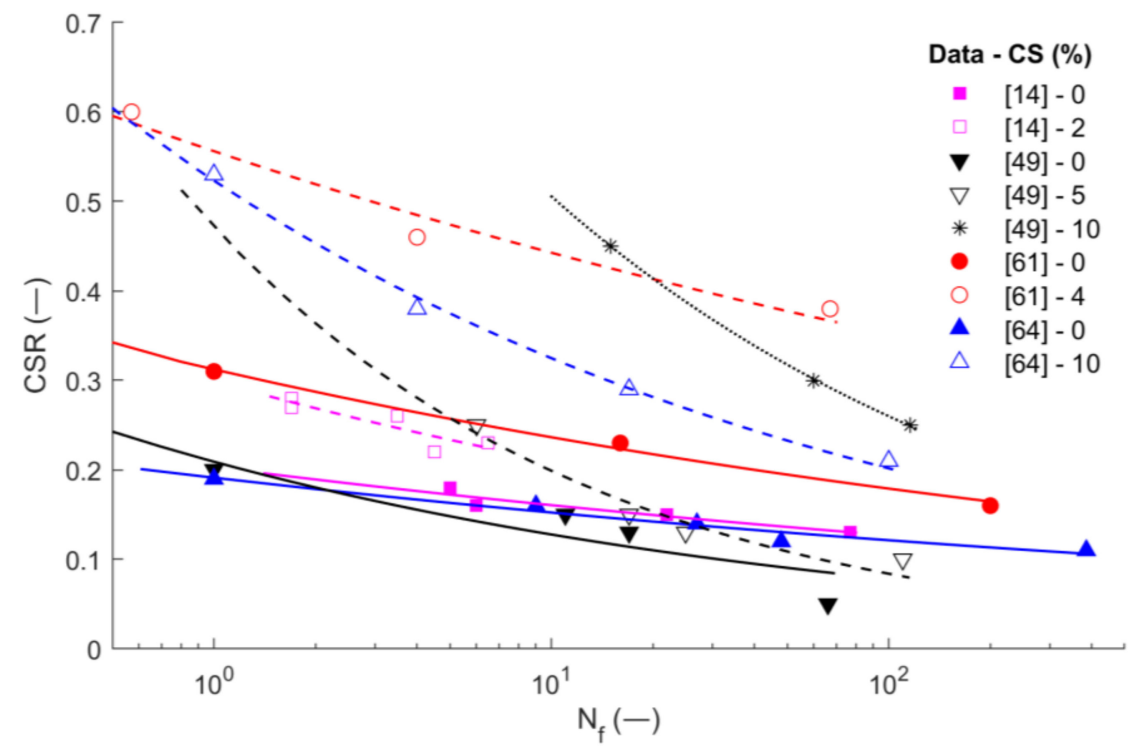

Figure 8. Cyclic Stress Ratio (CSR) against the number of cycles at failure $\left(\mathrm{N}_{\mathrm{f}}\right)$ after cyclic tests on loose $\left(D_{r} \leq 45 \%\right)$ untreated and treated sands (data collected from references in the legend; liquefaction resistance curves calculated via a power relation $\mathrm{CSR}=\mathrm{aN}_{\mathrm{f}}^{\mathrm{b}}$ ).

Gallagher and Mitchell [23] performed undrained cyclic triaxial tests on Monterey $\# 0 / 30$ sand $\left(D_{50}=0.44 \mathrm{~mm}\right.$, uniformity coefficient $C_{u}=1.64$, curvature coefficient $C_{c}=1.01$, specific gravity $\mathrm{G}_{\mathrm{S}}=2.65$ ) treated with $5-20 \%$ (by weight) CS content grout. Specimens were prepared by pluviating dry sand into liquid grout $\left(\mathrm{D}_{\mathrm{r}} \approx 22 \%, 3 \times 6.25\right.$ inches; gel time 4-28 h; curing time 40 h-56 d; confining stress of $100 \mathrm{kPa}$; frequency of $1 \mathrm{~Hz}$ ). Backpressurization was not performed for saturation and pore pressure was not recorded during the tests. They found that: (i) the CS treatment improved the deformation resistance of treated sand; (ii) the level of improvement was related to the CS content; (iii) samples treated with lower CS contents experienced more strain than samples treated with higher CS contents, for a given Cyclic Stress Ratio; (iv) the axial strain developed in cyclic test sand was not symmetric about the zero axis. According to their findings, CS contents of 5-10\% could be considered a good compromise between effectiveness and economic advantage to improve the sand liquefaction resistance.

Liao et al. [38] performed undrained cyclic triaxial tests on sand from a hydraulic fill $\left(\mathrm{D}_{50} \approx 0.4 \mathrm{~mm}, \mathrm{C}_{\mathrm{u}}=4.13, \mathrm{C}_{\mathrm{c}}=1.238, \mathrm{G}_{\mathrm{s}}=2.719, \mathrm{SP}\right)$. Dry sand was tamped in layers followed by grout permeation for specimen preparation $\left(\mathrm{D}_{\mathrm{r}}=50 \% \pm 3 \%\right.$; gel time $8 \mathrm{~min}$; curing time 7-28 d; consolidation stress of $98 \mathrm{kPa}$; CS content: unspecified; frequency of $0.5 \mathrm{~Hz}$ ). They obtained: (i) an increase up to 4-7-fold in the stress ratio needed to initiate liquefaction of treated sand after $28 \mathrm{~d}$ compared to the untreated sand; (ii) $8 \%$ and $24 \%$ increases in liquefaction resistance when curing time increase from $7 \mathrm{~d}$ to $14 \mathrm{~d}$ and $28 \mathrm{~d}$, respectively; (iii) very high stress ratios were required to activate the mechanism of pore pressure build-up in grouted sand compared to ungrouted sand; these high stresses caused a rapid increase in pore pressure at the initial loading stage, even if many more cycles could be withstood before reaching initial liquefaction.

Díaz-Rodríguez and Antonio-Izarraras [39] performed cyclic simple shear tests on Làzaro Càrdenas sand (uniform sand with low fines content, $\mathrm{C}_{\mathrm{u}}=2.71, \mathrm{G}_{\mathrm{s}}=2.67$ ). Specimens were prepared by pluviating dry sand into liquid grout. ( $\mathrm{D}_{\mathrm{r}}=40 \%, 40-100 \%$ for untreated sand only; curing time $3 \mathrm{~d}$; vertical stress of $0.3 \mathrm{~kg} / \mathrm{cm}^{2}$; CS content: $10-20 \%$; frequency of $1 \mathrm{~Hz}$ ). Liquefaction of $\mathrm{D}_{\mathrm{r}}=40 \%$ treated samples increased with increasing CS 
contents. They observed that: (i) the rate of pore pressure ratio increase was faster as CS content decreased; (ii) the untreated material failed in fewer loading cycles than treated material; (iii) peak-to-peak shear strain developed slower with loading cycles as the CS content increased, being the minimum for $C S=20 \%$, with a trend similar to that of the pore pressure ratio response.

Kodaka et al. [61] carried out undrained cyclic torsional shear (hollow cylinder) tests on specimens prepared by permeation of grout after water saturation $\left(D_{r}=40 \%, 100 \mathrm{~mm}\right.$ height, 100/60 mm outer/inner diameter (hollow cylinder); curing time 4 weeks; CS content: 4\%). According to their findings: (i) the liquefaction resistance of sand increased due to grouting; (ii) collapse condition corresponding to zero effective stress (i.e., pore pressure ratio $r_{u}=100 \%$ ) was not achieved; (iii) the development of strain was lower for treated sand.

Díaz-Rodríguez et al. [47] performed cyclic simple shear tests on Làzaro Càrdenas sand samples (poorly graded sand with $11.5 \%$ non-plastic silt-sized content, diameter corresponding to $10 \%$ passing $\mathrm{D}_{10}=0.07 \mathrm{~mm}, \mathrm{C}_{\mathrm{u}}=3.0, \mathrm{C}_{\mathrm{c}}=0.98$, SP-SM). Sand was directly pluviated into liquid grout $\left(\mathrm{D}_{\mathrm{r}}=40 \%, 60 \%, 22 / 70 \mathrm{~mm}\right.$ height/diameter; curing time $7 \mathrm{~d}$; vertical stress $29.4-88.2 \mathrm{kPa}$; CS content: $7.25-14.5 \%$; frequency of $1 \mathrm{~Hz}$ ). They found that: (i) loose and dense treated sand had a greater liquefaction resistance than loose and dense untreated material; (ii) pore pressure ratio increase was delayed in treated sand, becoming faster as CS contents were reduced (fastest for untreated sand).

Mollamahmutoglu and Yilmaz [63] performed cyclic triaxial tests on a clean sand $\left(\mathrm{G}_{\mathrm{S}}=2.62, \mathrm{SP}\right)$. Dry sand was tamped in layers, followed by water saturation and grout permeation $\left(D_{r}=50 \%, 140 / 70 \mathrm{~mm}\right.$ height/diameter; curing time $28 \mathrm{~d}$; two different grouts composed, respectively, of a mixture of saline solution with a ratio salt:water $=1: 9$ and $20 \%$ CS, and a ratio salt:water $=1: 12$ and $25 \%$ CS; frequency of $1 \mathrm{~Hz}$; the consolidation step was omitted). No failure was observed for treated samples over 1000 loading cycles, and after cyclic loading, additional unconfined compressive strength tests showed that treated samples exhibited little strength loss $(\approx 10 \%)$.

Porcino et al. [64] performed undrained cyclic simple shear and cyclic triaxial tests on Ticino silica sand $\left(\mathrm{D}_{50}=0.6 \mathrm{~mm}, \mathrm{C}_{\mathrm{u}}=1.3, \mathrm{G}_{\mathrm{S}}=2.68\right)$. Specimens were prepared by pluviation of dry sand followed by grout permeation $\left(\mathrm{D}_{\mathrm{r}}=45 \%\right.$ (also $75 \%$ for untreated sand), 22/80 mm height/diameter (simple shear), 140/70 mm (triaxial); gel time 60-90 min; curing time $24 \mathrm{~h}$ (up to $30 \mathrm{~d}$ for some simple shear tests); effective consolidation stress $100 \mathrm{kPa}$ (for both test types); CS content: $10 \%$; frequency of $0.05 \mathrm{~Hz}$ and $0.30 \mathrm{~Hz}$ for a few triaxial tests). They showed that: (i) treated sand exhibited little strain under cyclic loading if compared with that of untreated material; (ii) pore pressure development was different for treated and untreated sand; (iii) the effect of treatment was found equivalent to densification of untreated sand to $D_{r}=75 \%$; (iv) no significant increase in liquefaction resistance was obtained as curing time increased; $(v)$ the increase in loading frequency tended towards a higher cyclic resistance of treated sand.

Porcino et al. [48] performed undrained cyclic simple shear tests on Ticino silica sand $\left(D_{50}=0.6 \mathrm{~mm}, C_{\mathrm{u}}=1.3, \mathrm{G}_{\mathrm{S}}=2.68\right)$. Specimens were prepared by air-pluviation followed by grout permeation $\left(D_{r}=45 \%, 22 / 80 \mathrm{~mm}\right.$ height/diameter; gel time 60-90 min; curing time $24 \mathrm{~h}$; effective vertical stress $25-100 \mathrm{kPa}$; CS content: $10 \%$; frequency of $0.05 \mathrm{~Hz}$ ). The authors showed that: (i) liquefaction resistance of sand was improved by the treatment; (ii) at lower effective vertical pressure the level of improvement was greater; (iii) the effect of grouting was found equivalent to densification of untreated sand to $D_{r}=75 \%$.

Vranna and Tika [66] showed the results of cyclic triaxial on quartz sand $\left(\mathrm{D}_{50}=0.31 \mathrm{~mm}\right.$, $\mathrm{C}_{\mathrm{u}}=1.50, \mathrm{G}_{\mathrm{s}}=2.655$, named M31 sand). Samples were formed by moist tamping followed by grout permeation $\left(D_{\mathrm{r}}=14.4-59.5 \%, 100 / 50 \mathrm{~mm}\right.$ height/diameter; gel time $10-11 \mathrm{~h}$; curing time 5 times the gel time; isotropic pressure 100-300 kPa; CS content: 6, 10\%; frequency of $0.1 \mathrm{~Hz}$; no water saturation prior to testing). They pointed out that: (i) the cyclic response of $6 \%$ CS-treated sand was comparable to that of a weakly cemented sand (1\% white Portland cement content); (ii) the cyclic response of sand treated with $10 \%$ CS 
grout was not found significantly different from that of $6 \%$ CS grouted material; (iii) for increasing stress levels, the benefits of stabilization (both cementation and CS grouting) were reduced. In a later work, for cyclic triaxial tests carried out under similar conditions on the same type of sand, Vranna et al. [68] highlighted that: (i) the treated sand in the testing conditions had approximately two times the liquefaction resistance of the untreated one; (ii) the treated specimens had higher deformation resistance (i.e., untreated samples developed higher double amplitude axial strain during loading within the same number of cycles). Moreover, they confirmed that the increase in CS content (from 6 to $10 \%$ ) did not significantly affect the cyclic response of treated sand. In a recent study, Vranna and Tika [69] proved that the liquefaction resistance of a silty sand increased with rising CS content from $6 \%$ to $10 \%$ when relative density was less than $40 \%$, while for higher densities the liquefaction resistance for both CS concentrations were similar.

Ciardi et al. [14] performed cyclic triaxial tests on a uniform silica sand $\left(D_{50}=0.30 \mathrm{~mm}\right.$, $\left.\mathrm{C}_{\mathrm{u}}=1.6, \mathrm{G}_{\mathrm{s}}=2.65, \mathrm{SP}\right)$. Dry sand was pluviated into liquid grout $\left(\mathrm{D}_{\mathrm{r}}=18-30 \%\right.$ (treated sand), $100 / 50 \mathrm{~mm}$ height/diameter; gel time $\approx 2 \mathrm{~h}$; curing time $5 \mathrm{~d}$; isotropic pressure of $100 \mathrm{kPa}$; CS content: $2,5 \%$; frequency of $0.1 \mathrm{~Hz}$; no back-pressure saturation prior to testing). They showed that: (i) $2 \%$ CS content ('weak CS gel') was enough to increase the liquefaction resistance of grouted sand; (ii) the liquefaction resistance of $2 \%$ treated material was $\approx 28 \%$ greater than that of the untreated one after 15 cycles; (iii) the liquefaction resistance increased with increasing CS contents.

Salvatore et al. [49] performed cyclic triaxial tests on silica sand $\left(D_{50}=0.303 \mathrm{~mm}\right.$, $\left.C_{u}=1.6, G_{s}=2.65\right)$. Specimens were formed by dry sand deposition followed by grout permeation (no preliminary water saturation) $\left(D_{\mathrm{r}}=20.6-61.2 \%, 140 / 70 \mathrm{~mm}\right.$ height $/$ diameter; curing time $5 \mathrm{~d}$; effective consolidation pressure 100, $200 \mathrm{kPa}$; CS content: 5, 10\%). They found that: (i) liquefaction resistance increased with increasing CS contents; (ii) for a given $D_{\mathrm{r}}$ value, the peak pore pressure ratio developed slower for treated sand than for the untreated one.

Pavlopoulou and Georgiannou [70] carried out cyclic triaxial tests on M31 sand (76/38 mm height/diameter; curing time $50 \mathrm{~h}$; mean effective consolidation pressure 100, $200 \mathrm{kPa}$ ). Specimens were formed in loose and medium-dense states by sedimentation of sand in the hydrosol (10\% CS grout), and they were back-pressure saturated in a standard way. The authors found that: (i) despite a greater liquefaction resistance, the treated sand showed a softer response at the early loading stage, resulting in a faster pore water pressure and axial strain build up; (ii) (secant) stiffness measurements during cyclic loading revealed that the stiffness at the early loading stage was an order of magnitude lower for treated than for untreated loose sand; (iii) only dense treated sand had similar initial stiffness than loose untreated sand; (iv) a univocal trend between stiffness and cyclic strain was obtained for loose and dense treated and untreated sand.

\subsubsection{From Low to Medium Strain Levels}

Some studies showed that key soil parameters, like the initial shear modulus and damping ratio, are somehow affected by the CS treatment. Both the initial shear modulus and damping ratio increase because of CS grouting. However, there are controversial data on the magnitude of this increase. Spencer et al. [77] performed resonant column tests on sand samples (Nevada 120 sand; $D_{50}=0.15 \mathrm{~mm}, C_{u}=1.6$, uniform fine sand, $\mathrm{SP}$ ) treated with CS contents $4-9 \%\left(D_{r}=40 \%, 142 / 71 \mathrm{~mm}\right.$ height/diameter, gel time $\approx 3 \mathrm{~h}$, 10 times gel time curing time, and confining stress of $50 \mathrm{kPa}$ ). They found that: (i) the shear modulus of grouted sand increased with increasing silica content; (ii) the shear modulus was significantly higher for pure sand than for treated material; (iii) the damping ratio was practically unaffected by grouting at small strains. In a following work ([78]), the authors showed the results of resonant column tests on $D_{r}=50 \%$ sand samples. They observed that the shear modulus at small strain levels was higher for treated sand and that negligible effects on damping ratio were measured over the whole cyclic strain range. By way of 
example, Figure 9 shows the results from experimental tests reported in Spencer et al. [78]; G, D and $\gamma$ are the shear modulus, the damping ratio and the shear strain, respectively.

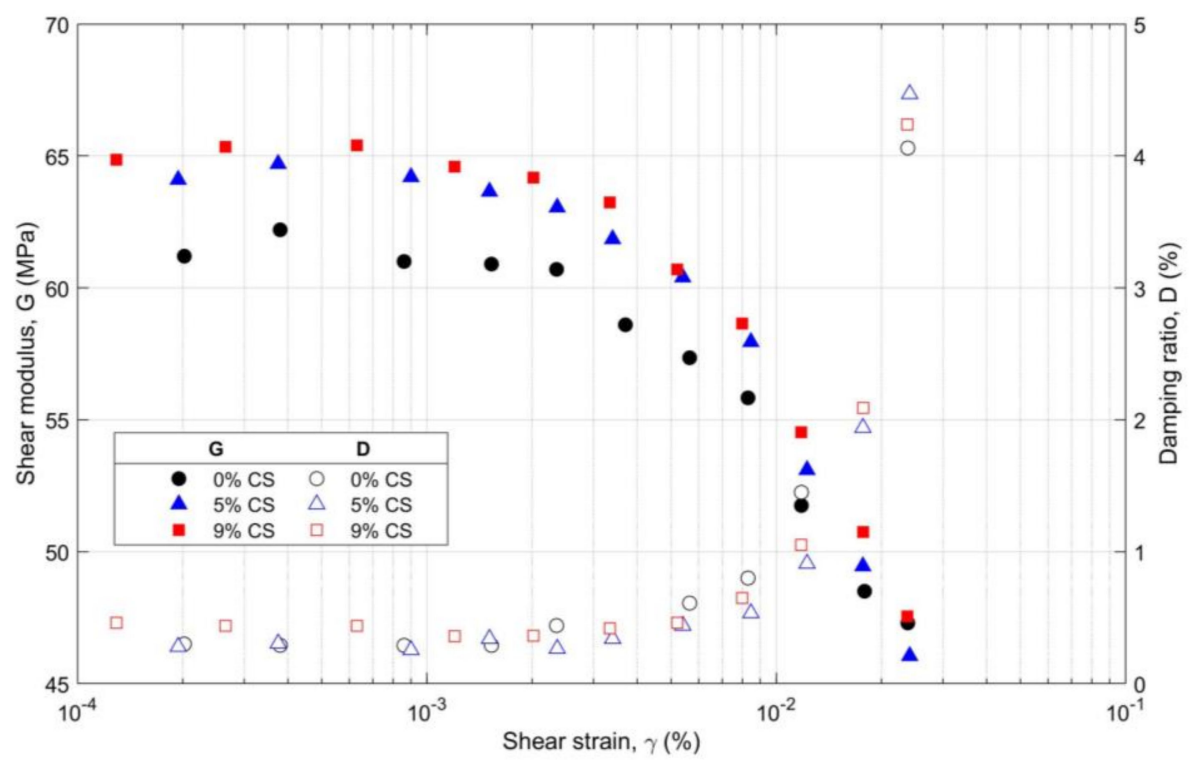

Figure 9. Experimental shear modulus (left axis) and damping ratio (right axis) versus shear strain from resonant column tests on CS-treated and untreated sand (data from [78]).

While in Spencer et al. $[77,78]$ negligible effects on damping ratio were found, Batilas et al. [79] observed a broader range of values from resonant column tests $\left(D_{r}=30-50 \%\right.$, $110 / 50 \mathrm{~mm}$ height/diameter specimens; gel time $2 \mathrm{~d}$; shear strain $10^{-5}-10^{-3}$; confining pressure $50-300 \mathrm{kPa}$; CS content: $6,10 \%$; clean sand and silty sand with $10 \%$ fines content). They found that: (i) the damping ratio increase is related to samples density, shear strain and confining pressure; (ii) both the shear modulus and damping ratio increased due to $10 \%$ CS treatment for clean and silty sand; (iii) the damping ratio increase varied from negligible values $\left(\mathrm{D}_{\mathrm{r}}=50 \%\right.$, medium shear strain and confinement of $\left.300 \mathrm{kPa}\right)$ up to $55 \%\left(D_{r}=30 \%\right.$, medium shear strain and confinement of $\left.100 \mathrm{kPa}\right)$; (iv) reducing the CS concentration from $10 \%$ to $6 \%$ by weight for clean sand $\left(D_{r}=50 \%\right)$ led to a reduction in the shear modulus and to an increase in the damping ratio ranging from $15 \%$ to $50 \%$, as the shear strain increased.

Results from bender element tests reported by Conlee et al. [24] showed that the initial shear modulus increased by $\approx 12 \%$ for $9 \%$ CS-treated sand compared to untreated sand, and by $\approx 14 \%$ for $5 \%$ CS-treated sand compared with $4 \%$ CS grouted sand. Krishnan et al. [50] found that both damping ratio and initial shear modulus significantly increased for treated samples with increasing curing time. Salvatore et al. [49] showed that the shear wave velocity was greater for treated than for untreated sand and observed an increase over time of the shear wave velocity measured by bender element tests on treated sand. This agrees with the increase in gel strength as curing time increases.

In conclusion, since it is not clear how much the damping ratio and the initial shear modulus are affected by CS grouting, the behavior of treated sand at small strain levels needs to be studied more thoroughly.

\subsubsection{Physical Modeling Tests}

Compared to laboratory tests, which point out some important aspects on the behavior of small-sized soil elements, the tests on physical models allow investigation of larger volumes of soil and attainment of more complete information on the behavior of the CS-soil system.

The available centrifuge model tests on CS-treated materials show that the deformation exhibited by stabilized soil is significantly lower than for untreated material. Gallagher 
et al. [25] pluviated dry Nevada No. 120 sand for a thickness of approximately $200 \mathrm{~mm}$ (to simulate $10 \mathrm{~m}$ prototype soil deposit at $50 \mathrm{~g}$ ) into a $46 \times 37 \mathrm{~cm}$ laminar box, $26 \mathrm{~cm}$ height. The sand was packed at a relative density of $40 \%$, and the CS grout $(6 \%$ CS by weight) was delivered by permeation under a vacuum during $13 \mathrm{~h}$ saturation. Gel time was $56 \mathrm{~h}$ and curing time $240 \mathrm{~h}$. The pore pressure response was not measured. The model was subjected to 2 shaking events parallel to the base of the box, each of 20 loading cycles (sinusoidal input) at $2 \mathrm{~Hz}$, with peak accelerations $0.2 \mathrm{~g}$ and $0.25 \mathrm{~g}$ in prototype units. They found that liquefaction did not occur during either shaking event: shear strains of $\pm 0.5 \%$ and $\pm 1 \%$ were measured in the first and second shaking events, respectively, and $0.3 \%$ and less than $0.1 \%$ settlements were recorded at the center of the model during the first and second events, respectively. These values were up to 25 times less than those recorded by Taboada [108] in a similar centrifuge test for untreated sand.

Pamuk et al. [62] performed physical modeling tests on pile foundations in liquefiable sand (Nevada 120 sand; $D_{50}=0.15 \mathrm{~mm}, \mathrm{G}_{\mathrm{s}}=2.67$ ) treated by $5 \% \mathrm{CS}$ grout. The model consisted of a laminar box with a 3-layer soil system with a $2 \times 2$ end-bearing pile group connected by a pile cap, characterized by a model height of $20 \mathrm{~cm}$ and tested at a centrifuge acceleration of $50 \mathrm{~g}$. Some interesting results were obtained by the authors: they showed that the treated soil did not liquefy, and therefore that it was able to transmit shear stresses from the base shaking through the surface of the model, with only small amplification of the input acceleration at shallow depths both in free-field and at the pile cap. Acceleration records along the soil profile after CS treatment indicated that there was substantially no loss of soil strength and stiffness during shaking. The free-field lateral displacement profiles were smaller when sand was treated with CS than those recorded in the model without soil treatment, and the soil close to the pile cap did not fail when CS was used. The CS treatment produced a dramatic decrease $(97 \%)$ in pile bending moments, compared to the moments recorded for the untreated model; the lateral deformation of the ground surface, for CS-treated soil, was about $5 \%$ of that of the untreated soil.

Conlee et al. [24] performed centrifuge tests on two models. Each model was characterized by 2 slopes with $3^{\circ}$ inclinations towards a central channel. It consisted of a bottom layer of Monterey $0 / 30$ sand, and of a central liquefiable Nevada sand layer that was overlain by a compacted Yolo loam layer. Grout was permeated under a vacuum. Resonating time for the rigid gel was between 16 and $120 \mathrm{~h}$, depending on initial CS content (4-9\%). Eight shaking events were applied to the models, with centrifugal acceleration of $15 \mathrm{~g}$ (a sinusoidal wave applied for 20 cycles at a frequency of $2 \mathrm{~Hz}$ ). The authors found significant deformation reduction in grouted sand, with ground deformations progressively decreasing with increasing CS contents. Moreover, lateral spreading in slopes laying on treated liquefiable layers was reduced.

\subsection{Mechanical Behavior under Static Loading Conditions}

\subsubsection{Monotonic Loading}

Colloidal silica treated soil can be easily subjected to unconfined compression strength (UCS) tests, with resulting UCS values that depend on the percentage of silica diluted in the stabilizing grout. Studies unanimously demonstrated that UCS values increase as silica contents and the age of samples increase (e.g., [13,23,63,69,71]). Moreover, treated soil subjected to monotonic loading shows enhanced dilative response (e.g., [48,49,61,70-72,74]) (Figure 10).

However, it is still not fully clear whether this depends on the effect of bonding the grains, on the effect of an equivalent densification due to the presence of silica solids, or more likely on a combination of both factors. In addition to enhanced dilation, the peak shear resistance of treated soil is higher than for untreated material, and it increases with increasing silica contents and samples' age (e.g., $[14,48,49,70,72])$. The phase transformation and critical state lines also move up for treated sand $[60,64,70]$. 

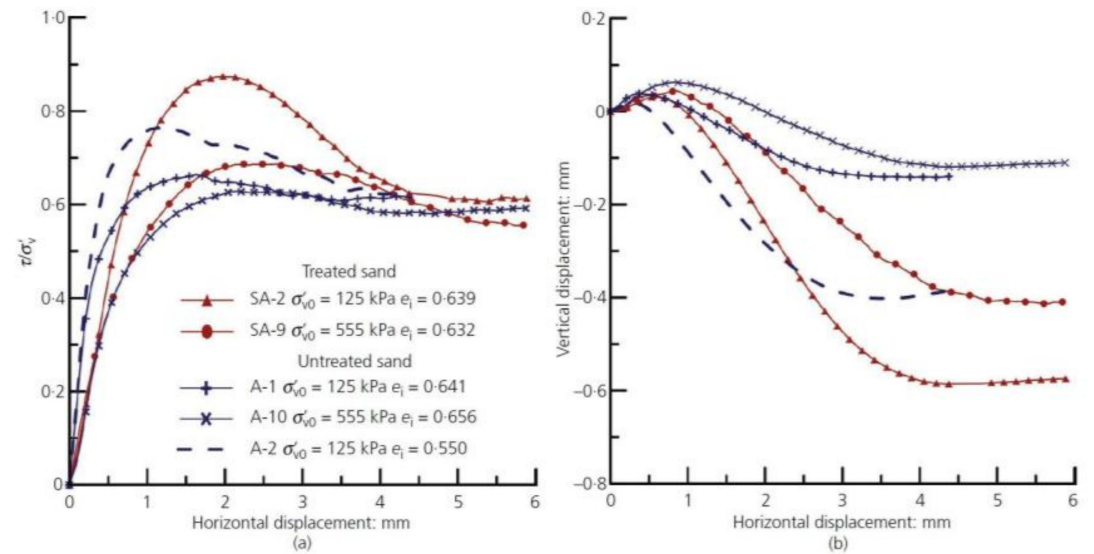

Figure 10. Direct shear stress results for treated and untreated sand: (a) stress ratio vs. horizontal displacement; (b) vertical vs. horizontal displacement [71].

The overall effect of CS treatment can be mainly viewed as an increase in the cohesive properties of soil, with minor effects on the peak angle of shearing resistance (e.g., $[14,48,50,61,65,70-73])$, even though there seems to be a strong test-type dependence.

Soil samples subjected to monotonic loading after cyclic shearing showed little shear resistance degradation and deformation levels related to the amount of strain developed in the previous loading stage $[23,63,65,68,69]$.

Most of the studies described in Section 5.1.1 also analyzed the behavior of CS-treated soil under monotonic loading. Therefore, the test details (materials' characteristics, specimen formation method, etc.) that have previously been described are not reported again in the following paragraphs (unless there are significant differences to be mentioned), and only the main conclusions of the studies are highlighted.

Kodaka et al. [61] performed drained and undrained torsional shear tests $\left(\mathrm{D}_{\mathrm{r}}\right.$ up to $80 \%$ for untreated sand; effective confining stress $50-200 \mathrm{kPa}$; velocity $0.5 \% / \mathrm{min}$ ). The authors found that: (i) treated material exhibited enhanced characteristics of dilatancy and higher shear stress at failure under the same confining stress; (ii) the dilation region expanded for treated sand; (iii) the slope of the failure line, obtained from undrained torsional shear tests, slightly increased and its position moved upward.

From undrained monotonic simple shear tests $\left(D_{\mathrm{r}} \approx 45 \%\right.$; effective consolidation stress $25-150 \mathrm{kPa}$; velocity $0.13 \mathrm{~mm} / \mathrm{min}$ ), Porcino et al. [64] obtained: (i) more dilation and higher peak stress ratios for treated specimens than for untreated ones; (ii) cohesion intercept of $3 \mathrm{kPa}$ and internal friction angle of $37.4^{\circ}$ for treated sand (no cohesion and friction angle at ultimate state of $34.4^{\circ}$ for untreated material); (iii) phase transformation line higher for treated samples.

Enhanced dilative behavior was also detected from drained triaxial tests on loose sand by Porcino et al. [48] (effective consolidation stresses $20-400 \mathrm{kPa}$; velocity $0.03 \mathrm{~mm} / \mathrm{min}$ ). They also found that the peak failure envelopes of treated and untreated material were almost parallel in the mean confining pressure-deviatoric stress plane, with a $29 \mathrm{kPa}$ increase in cohesion $\left(c^{\prime}\right)$ for the treated sand and a negligible increase (about $1^{\circ}$ ) in the peak friction angle $\left(\phi^{\prime}\right)$.

Georgiannou et al. [71] performed drained triaxial and direct shear test on M31 sand (dry sand pluviated into liquid grout; $\mathrm{D}_{\mathrm{r}} \approx 37-93 \%$ (untreated sand) and $\approx 2-68 \%$ (treated sand); 100/50 mm height diameter (triaxial test), 24/60 mm height/diameter (direct shear, circular shape); gel time $10 \mathrm{~h}$; curing time $50 \mathrm{~h}$; effective consolidation stresses $100-700 \mathrm{kPa}$ (triaxial), $53-555 \mathrm{kPa}$ (direct shear); CS content: $10 \%$; strain rate $0.025(0.005) \mathrm{mm} / \mathrm{min}$ in triaxial tests (direct shear)). Based on the results obtained, the authors concluded that the behavior of treated loose sand under direct shear resulted comparable to that of untreated dense sand and hypothesized a curved failure envelope for medium-dense sand subjected to direct shear tests $\left(\mathrm{c}^{\prime}=0 \mathrm{kPa} ; \phi^{\prime}=41.3^{\circ}\right.$ at vertical effective stress $\sigma_{\mathrm{v}}^{\prime}=125 \mathrm{kPa}$ and $\phi^{\prime}=34.9^{\circ}$ at $\sigma^{\prime}{ }_{\mathrm{v}}=555 \mathrm{kPa} ; \phi^{\prime}=32.5^{\circ} \mathrm{c}^{\prime}=0 \mathrm{kPa}$ for untreated material). Furthermore, 
they obtained $c^{\prime}=14 \mathrm{kPa}$ and $\phi^{\prime}=38.3^{\circ}-35^{\circ}$ at effective confining pressure in the range $100-700 \mathrm{kPa}$ from drained triaxial tests on treated sand.

Wong et al. [72] performed direct shear tests on Leighton Buzzard sand $\left(D_{50}=1.2 \mathrm{~mm}\right.$, $C_{u}=1.26, G_{s}=2.65$ ) and kaolin clay (plastic limit 0.32, liquid limit 0.64 ), the latter not being discussed in this paper. Sand specimens were formed by dry sand deposition followed by grout permeation (squared samples $60 \times 60 \mathrm{~mm}, 20 \mathrm{~mm}$ height; gel time $\approx 1 \mathrm{~h}$; curing time 1-4 weeks; vertical effective stress $100-300 \mathrm{kPa}$; CS content: $34 \%$ [109]; shearing rate $0.001 \mathrm{~mm} / \mathrm{min}$ ). They found that: (i) the maximum ratio between the shear stress and the effective vertical pressure recorded during the tests was always greater for treated sand than for untreated over the whole range of adopted vertical pressure; (ii) a marked increase in peak shear stress ratio was only observed for $200 \mathrm{kPa}$ vertical pressure, while for $100 \mathrm{kPa}$ and $300 \mathrm{kPa}$ similar values were obtained irrespective of curing time; (iii) treated sand samples were always dilatant (greatest volume expansion for the 4 week cured samples); (iv) the increase in cohesion $(26 \mathrm{kPa})$ and in peak friction angle $\left(8^{\circ}\right)$ was notable.

Ciardi et al. [14] showed the results from direct shear tests (dry sand pluviated into liquid grout; $\mathrm{D}_{\mathrm{r}}=22-33 \%, 60 \mathrm{~mm}$ squared specimens, $20 \mathrm{~mm}$ height; $\mathrm{CS}$ content: $2 \%$; strain rate 0.03 or $0.0015 \mathrm{~mm} / \mathrm{min}$ for untreated or treated sand, respectively). They observed that: (i) the failure envelope for treated sand was characterized by a cohesion of approximately $8 \mathrm{kPa}$, while the peak friction angle was practically unaffected by treatment; (ii) the dilatancy was less affected by treatment than the initial volume contraction during loading.

Figure 11 shows the increase in the failure line intercept and in peak friction angle for different CS-treated materials subjected to monotonic tests. It should be stressed that the results presented in Figure 11 comes from different test types on different materials under different testing conditions, including use of different commercial CS solutions. In Figure 11, the increase in $\phi^{\prime}$ ranges from a minimum of $1.2 \%$ ([14]) to a maximum of $19.5 \%$ ([72]) compared to the values of the untreated material.

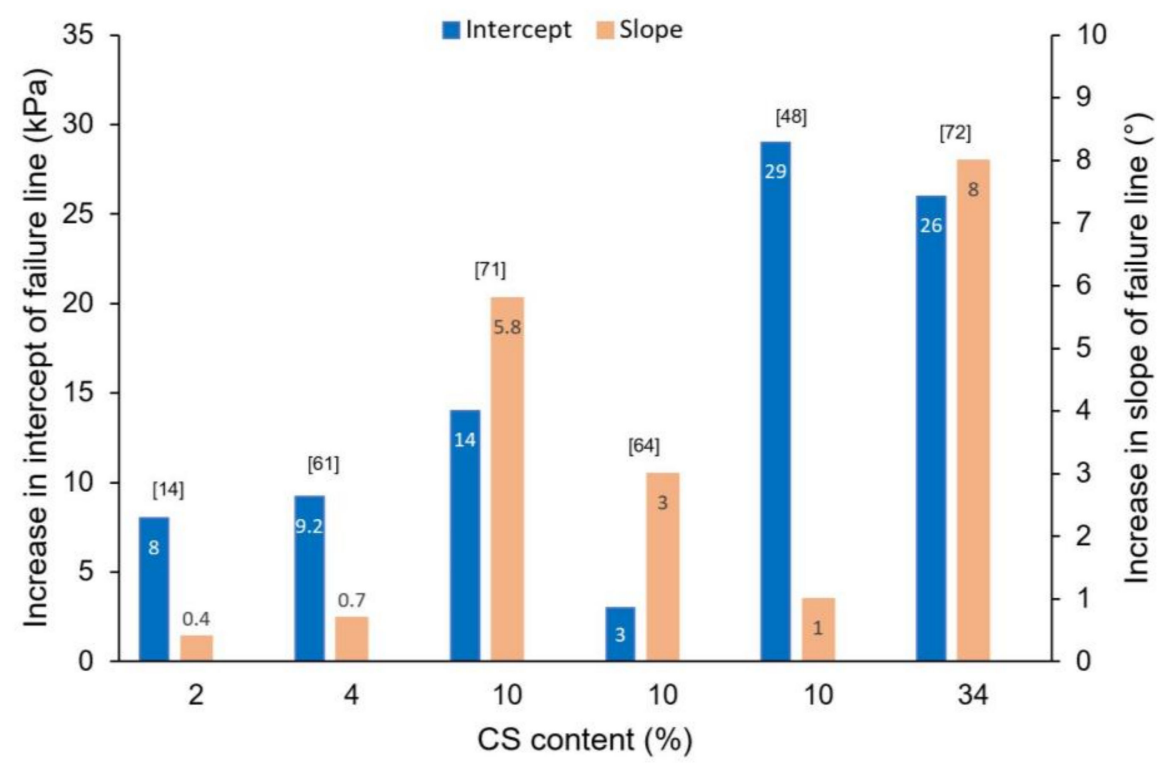

Figure 11. Increase in failure line intercept (left axis) and internal friction angle (right axis) after monotonic tests (data collected from the references in the plot; data from triaxial tests for [71] for normal effective stress $<200 \mathrm{kPa}$ ).

Recently, some studies have pointed out that there is not a clear trend of $c^{\prime}$ and $\phi^{\prime}$ increasing with CS contents. Krishnan et al. [50] performed undrained triaxial tests on poorly graded cohesionless soil $\left(\mathrm{D}_{10}=0.47, \mathrm{C}_{\mathrm{u}}=2.67, \mathrm{G}_{\mathrm{s}}=2.69\right)$. Specimens were prepared by dry sand compaction followed by grout permeation $\left(D_{r}=30,40,60 \%, 100 / 50 \mathrm{~mm}\right.$ height/diameter; gel time $7 \mathrm{~h}$; 3-28 d curing time; confining stress $100-300 \mathrm{kPa}$; CS content: 
7.5-30\%; strain rate $1.2 \mathrm{~mm} / \mathrm{min}$; unconsolidated tests). The authors concluded that: (i) both friction angle and cohesion increased with increasing CS contents to a limit, after which they decreased; (ii) no significant increase was observed over a $7 \mathrm{~d}$ curing time; (iii) a colloidal silica content $12.5 \%, 11 \%$ and $10 \%$ can be assumed as optimum to treat $\mathrm{D}_{\mathrm{r}}=30 \%$, $40 \%$ and $60 \%$ sand samples, respectively.

Nouri Delavar and Noorzad [73] performed drained triaxial tests on clean sand with varying fines content $(0 \%, 10 \%, 20 \%, 30 \%, 40 \%)$. Babolsar sand $\left(\mathrm{D}_{50}=0.19 \mathrm{~mm}, \mathrm{G}_{\mathrm{s}}=2.74\right)$ and Babol silt $\left(D_{50}=0.02 \mathrm{~mm}\right.$, fine content $\left.87.7 \%, \mathrm{G}_{\mathrm{s}}=2.55\right)$. Specimens were prepared by wet soil tamping (Babolsar sand and Babol silt mixed at different ratios, Silt content 0-40\%; curing time $3 \mathrm{~d}$; confining pressure 100-500 kPa; CS content: 5-30\%; strain rate $0.05 \mathrm{~mm} / \mathrm{min}$; no back-pressurization, saturation under water under a suction of $800 \mathrm{kPa}$ for $2 \mathrm{~d}$ ). The results showed that soil cohesion increased as CS content increased for all the fine contents investigated, and the internal friction angle first increased and then decreased with increasing silica contents.

The results of drained triaxial tests performed by Salvatore et al. [49] $\left(\mathrm{D}_{\mathrm{r}}=20-35 \%\right.$; curing time $5 \mathrm{~d}$ ( $15 \mathrm{~d}$ to evaluate the effects of curing time); effective consolidation stresses 100-300 kPa; CS content: 1.7, 5\%) showed that: (i) the ratio of the deviatoric over mean effective confining stress was higher (in the range 10-25\%) for treated sand for consolidation pressures of 100-300 kPa; (ii) the dilative behavior was significantly improved for treated sand.

Pavlopoulou and Georgiannou [70] performed a series of direct shear tests on 'Longstone' sand $\left(\mathrm{D}_{50}=0.15 \mathrm{~mm}, \mathrm{G}_{\mathrm{S}}=2.64\right)$ and M31 sand (normal effective stress $110-550 \mathrm{kPa}$; $\mathrm{D}_{\mathrm{r}}=43-93 \%$ ) and drained and undrained triaxial tests on M31 treated by $10 \%$ CS (initial effective stresses ranging between 100 and $2000 \mathrm{kPa}$ ). They obtained that: (i) the treated sand exhibited enhanced dilation; (ii) the peak strength was higher for treated sand but stress-level dependent, reflecting the enhanced dilative behavior with decreasing stress level; (iii) the stress ratio at critical state was the same for treated and untreated sand; (iv) the critical state line of treated soils were higher than for the untreated ones and (v) the small strain stiffness was higher for treated than for untreated material, under both drained and undrained loading conditions. The reduced small strain stiffness of treated sand during monotonic loading (that the authors also reported during cyclic loading, Section 5.1.1) was previously observed by Ciardi et al. [67], who found that the small strain stiffness of treated sand was lower than for untreated sand and it decreased with increasing CS contents.

Triantafyllos et al. [74] performed undrained and drained triaxial compression tests on stabilized M31 sand (sand pluviation into liquid grout; curing time $50 \mathrm{~h}$; initial mean effective stresses $100-6000 \mathrm{kPa}$; CS content: $10 \%$; strain rates $0.005-0.05 \mathrm{~mm} / \mathrm{min}$ ). The authors showed that: (i) there is a unique critical state line for treated sand that lays above that of untreated material, even though at high stresses the two lines tend to converge in the skeleton void ratio-mean effective stress plane; (ii) the treated material is significantly more dilative than the untreated one; (iii) at ultimate strength, both materials attained the same stress ratio; (iv) the loose treated material was more compressible with increasing stress levels (less difference was detected for denser sand); (v) in the initial shearing phase as well as in isotropic compression, loose treated sand appeared to be more compressible.

Vranna and Tika [69], while performing undrained monotonic tests on silty sand stabilized with CS (no pore pressure measurements), found: (i) a brittle response of the treated soil and increased maximum strength, if compared to the strain-hardening behavior of untreated material; (ii) an improved post-cyclic behavior of treated sand, for which the undrained shear strength, in post-cyclic monotonic tests, was similar to that exhibited by treated specimens that were not previously cyclically tested.

\subsubsection{Soil Compressibility}

Although the soil compressibility is a crucial aspect in civil design because of the consequences it can have on the performance of structures and infrastructures, few data on compressibility and settlements of grouted material have been reported in existing studies 
and it is still controversial whether CS grouting enhances or reduces the compressibility of soil. However, recent studies seem to agree that a loose treated sand subjected to isotropic or $1 \mathrm{D}$-confined compression loading is more compressible than the untreated counterpart $[14,67,70,74]$. It could be speculated that the enhanced compressibility is related to the viscous nature of gel, which tends to enhance slippage between grains [71]; according to Pavlopoulou and Georgiannou [70], the gel being damaged during normal compression forces free water to flow out of the pores, resulting in a different (denser) state of the material. However, these possible explanations need to be further investigated.

Towhata and Kabashima [37] pointed out that $4.5 \%$ and $6.5 \%$ CS grouted sand specimens exhibited more volumetric strain than the ungrouted sand during isotropic consolidation at a given stress level. They also showed that the greatest contraction was exhibited by sand treated with $4.5 \%$ CS, concluding that "the present method of grouting is different from the conventional solidification and rigid bonding of particles". Georgiannou et al. [71] compared oedometer results with those obtained from isotropic normal compression. Samples were formed by pluviating dry M31 sand into liquid grout (diameter $60 \mathrm{~mm}$; gel time $10 \mathrm{~h}$; curing time 50 h; CS content: 10\%). While deformations exhibited under isotropic compression were similar for both materials, the treated sand exhibited more volumetric strain than the untreated material over the entire range of vertical pressures under normal compression.

Similar results were found by Ciardi et al. [14], who observed a strong dependence of deformation on CS content upon loading in 1D-confined compression tests. Specimens were formed according to two different methods: dry sand pluviated into liquid grout (method 1); dry sand poured into a mold followed by the grout permeation (method 2) $\left(\mathrm{D}_{\mathrm{r}}=12-22 \%, 20 / 71 \mathrm{~mm}\right.$ height/diameter; gel time $\approx 2 \mathrm{~h}$; curing time $5 \mathrm{~d}$; CS contents: 2-13\%). Each loading/unloading step kept for at least $24 \mathrm{~h}$; test results are shown in Figure 12 , where $\varepsilon_{\mathrm{v}}, \sigma_{\mathrm{vc}}{ }^{\prime}, \mathrm{p}_{\mathrm{a}}$ and $\mathrm{CS}_{\mathrm{W}}$ are the vertical strain, vertical effective consolidation pressure, atmospheric pressure and silica content by weight, respectively. They found that: (i) the compressibility of treated samples was greater than that of the untreated material over the whole range of investigated effective stress; (ii) during loading, regardless of the specimens' formation procedure, test results showed a strongly CS content-dependent behavior, i.e., the volumetric strain did not increase linearly with increasing CS content for a given pressure, and for CS content $>5 \%$ the stress-strain curves were comparable with those for 5\% CS-treated material (Figure 12a); (iii) the unloading paths were practically unaffected by the presence of gel, i.e., they had a similar slope in the stress-strain plane (Figure 12b), suggesting that the elastic recovery was almost exclusively due to the soil skeleton.

On the contrary, Wong et al. [72] reported that the vertical strain in oedometer tests on $34 \%$ CS-treated sand (dry sand poured into mold followed by grout permeation; diameter $75 \mathrm{~mm}$; gel time $\approx 1 \mathrm{~h}$; each loading/unloading step kept for at least $24 \mathrm{~h}$ ) was significantly lower than that of the untreated one. According to the authors, the stiffer behavior of treated sand was due to the gel filling the pore space: in natural sand, particles are free to rearrange upon compression, while in grouted sand, the particles rearrangement is limited due to the presence of CS gel.

Pavlopoulou and Georgiannou [70] performed oedometer tests on M31 and 'Longstone' sand (Section 5.2.1) treated by $10 \%$ CS. Specimens were directly formed within the testing apparatus by sedimentation in the grout. Samples were prepared at different relative densities, and they found that higher volume changes were achieved in treated compared to untreated sands over the whole range of $\mathrm{D}_{\mathrm{r}}$.

Triantafyllos et al. [74] showed the compression curves of treated and untreated M31 sand after isotropic compression. They found different consolidation curves for treated and untreated material, concluding that: (i) treated sand was more compressible than untreated one with increasing stress levels; (ii) for denser sand, the differences were smaller; (iii) treated sand exhibited loading rate-independent behavior. 
a)
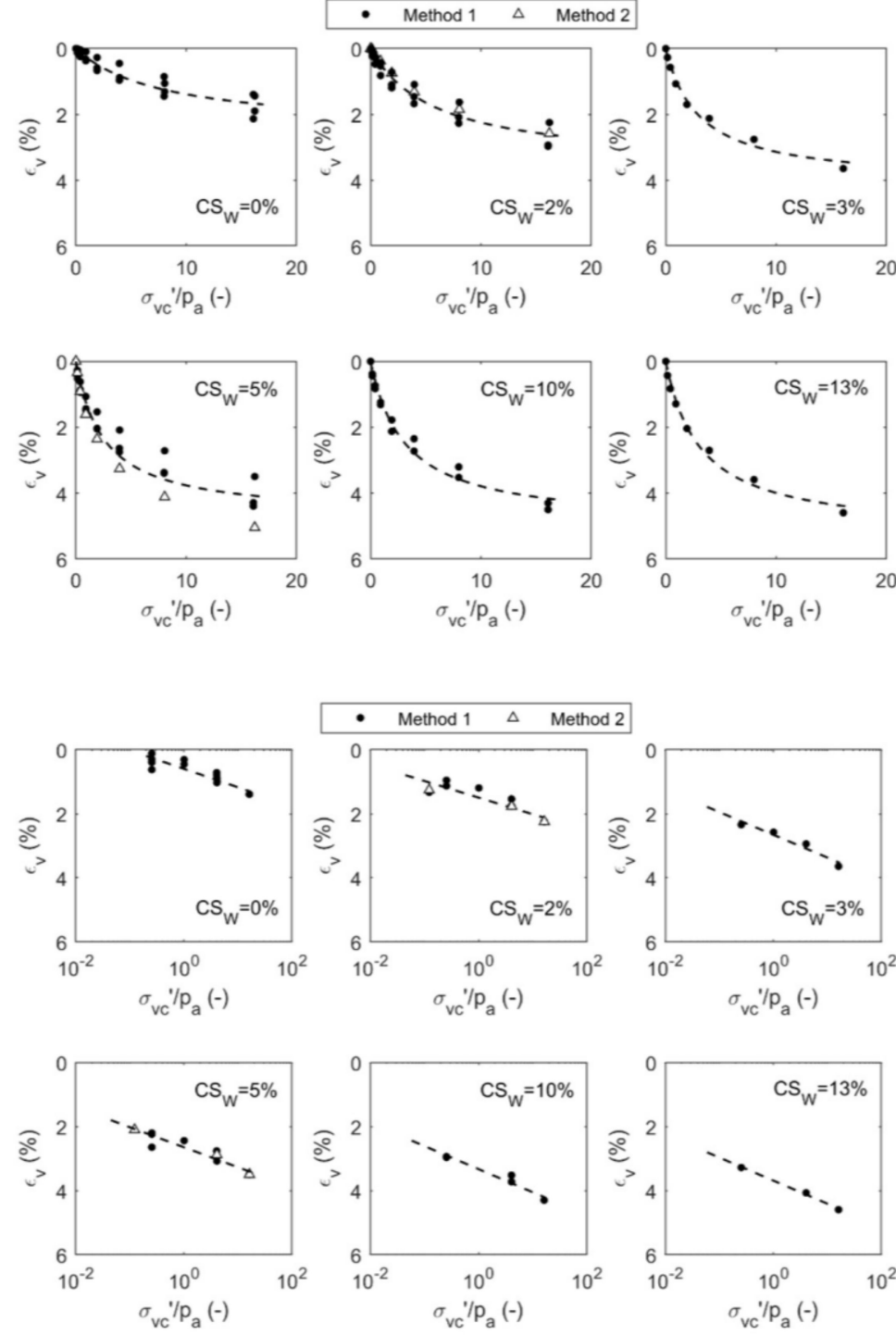

Figure 12. Oedometer test results on CS-treated and untreated sand): (a) loading path (linear abscissa); (b) unloading path (semi-log abscissa) (mod. from [14]).

\subsection{Effects of Gel Age on the Mechanical Behavior of Stabilized Soil}

The gel strengthening over time leads to an improvement over the same period of the mechanical properties of grouted soils. For a given laboratory test on stabilized soil, the soil-gel performance increases with increasing curing time. Many studies $[13,23,63,110]$ have shown that the unconfined compressive strength increased as curing time increased, depending on CS content value. For $27.5 \%$ CS content, Persoff et al. [13] showed UCS values of stabilized Monterey sand samples of $\approx 400 \mathrm{kPa}$ after $7 \mathrm{~d}$ : moreover, the strength of samples with $19.7 \%$ CS after $7 \mathrm{~d}$ was $350 \mathrm{kPa}$ and it increased up to $490 \mathrm{kPa}$ after 30 days' immersion in water. Persoff et al. [13] showed that the UCS of material treated with 10-20\% CS increased proportionally with the concentration of silica particles. Similar results were obtained by Gallagher and Mitchell [23] for samples treated with 5-20\% CS. Moradi and Seyedi [111] found that the UCS of a stabilized silty sand (0-30\% silt content) increased after a period of 6 weeks and Yonekura and Miwa [112] observed that the UCS of treated soil samples was still increasing after 3 years. More recently, Georgiannou et al. [71] showed that the UCS of colloidal silica treated sand samples with $10 \%$ silica concentration slightly increased (about 15\% more) with increasing curing time. Figure 13 shows the pocket penetrometer resistance (PPR) against curing time $\left(\mathrm{t}_{\mathrm{c}}\right)$, for sand treated with different silica contents. 


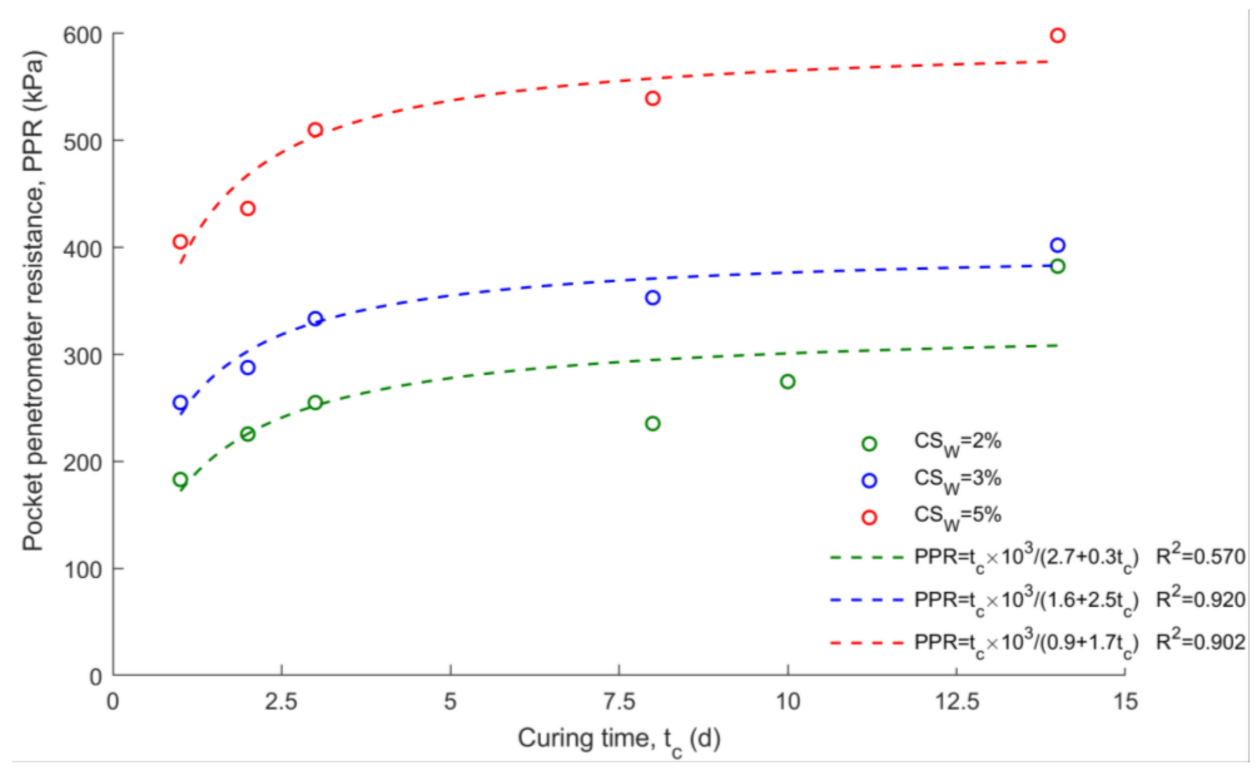

Figure 13. Pocket penetrometer resistance of CS-treated sand versus curing time for different CS contents (mod. from [107]).

Spencer et al. [78] found that the initial shear modulus of 5\% CS-treated sand measured at time intervals over $28 \mathrm{~d}$ in a resonant column test increased by $\approx 6 \mathrm{MPa}$, without apparently having reached an ultimate value. Krishnan et al. [50] observed that the shear modulus increased by $\approx 130 \%$ after $3 \mathrm{~d}$ curing time and by $\approx 1001 \%$ after $28 \mathrm{~d}$ while the damping ratio increased by $\approx 106 \%$ after $3 \mathrm{~d}$ up to $\approx 151 \%$ after $28 \mathrm{~d}$ for $\mathrm{D}_{\mathrm{r}}=30 \%$ soil samples. Salvatore et al. [49] showed that the shear wave velocity of a 5\% CS grouted triaxial sand specimen, measured by bender element tests at different confining pressures over $24 \mathrm{~d}$, was higher than that of untreated material and progressively increasing with time. The rate of increase was significant up to $9 \mathrm{~d}$, after which the increase continued at a slower rate. Furthermore, they observed that the peak stress ratio exhibited by $5 \%$ CS grouted dense sand (relative density $60 \%$ and $200 \mathrm{kPa}$ confining stress) after drained monotonic triaxial tests increased as curing time increased from $5 \mathrm{~d}$ to $15 \mathrm{~d}$. Vranna et al. [68] stated that increasing curing time above $2 \mathrm{~d}$ resulted in significantly higher stiffness of treated samples in monotonic triaxial tests, while curing times up to 2 months did not have much effect on the peak deviatoric stress of a 10\% CS-treated sample. An increase in peak deviatoric stress of $\approx 25 \%$ was measured after 1 year, even though, after the peak, the stress-strain response tended to converge to that of sand cured for $2 \mathrm{~d}$.

\subsection{Hydraulic Conductivity}

Experimental results highlighted that CS grouting causes a dramatic decrease in the initial hydraulic conductivity $(\mathrm{k})$ of soil and typical clay-like values are expected in sands after the treatment (e.g., $[13,14,48,66,72])$. Past research studies pointed out that $\mathrm{k}$ decreases as CS content increases (e.g., $[13,17])$; this decrease in $\mathrm{k}$ is ascribed to the structure of the gel, which is essentially made of silica chains forming a micro-porous network (CS content-dependent) through which water can flow [44,58]. In the untreated soil, the water flow is mainly governed by the amount and size of pore space, while in the gelled soil the water flow is mainly governed by the amount and size of the small pore space within the gel. Figure 14 shows hydraulic conductivity values for different sands treated with different CS contents. 


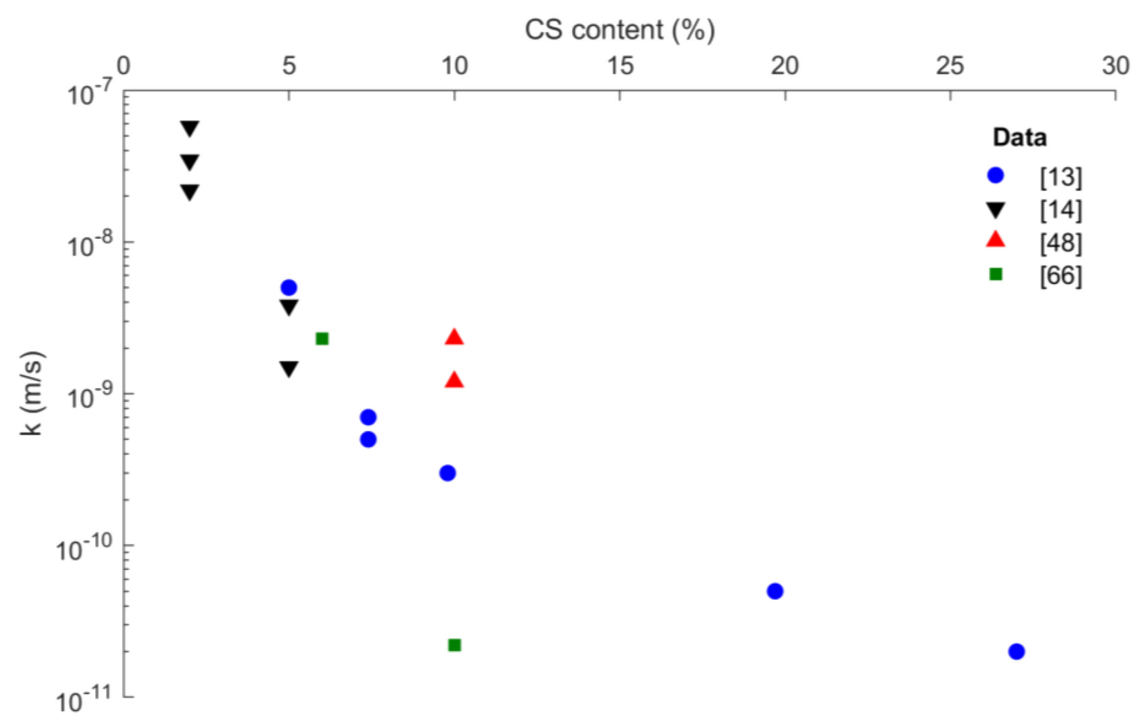

Figure 14. Hydraulic conductivity versus colloidal silica content for different CS-treated materials (data collected from references in the legend; data for Monterey 0/30 sand for [13]).

Reducing $\mathrm{k}$ is the main goal when CS is used to form impervious barriers and, more generally, to control locally the groundwater flow $[17,89,96]$, but it may represent a critical side-effect if the CS treatment is used in soil improvement against liquefaction. Since the grout viscosity increases over time, the change in soil permeability during grouting significantly affects the mechanism of grout delivery, reducing the grout flow $[52,82]$.

Table 1 shows significant results obtained from hydraulic conductivity measurements on CS grouted materials for both liquefaction mitigation and soil remediation.

Table 1. Significant studies on the effects of CS grouting on the soil hydraulic conductivity.

\begin{tabular}{|c|c|c|c|c|}
\hline Reference & Tested Soil(s) & Test Type & Specimen Formation, Testing Details & Main Findings \\
\hline [17] & $\begin{array}{l}\text { Hanford sand, Los } \\
\text { Banos sand } \\
\text { (from quarry) }\end{array}$ & $\begin{array}{l}\text { Flexible wall } \\
\text { permeameter }\end{array}$ & $\begin{array}{l}\text { Three kinds of samples: } \\
\text { (1) prepared by pouring sand into liquid grout; } \\
\text { (2) prepared by grout injection into sandpacks; } \\
\text { (3) collected from field }\end{array}$ & $\begin{array}{l}\text { Sands with initial } \mathrm{k} \approx 10^{-4} \mathrm{~m} / \mathrm{s} \\
\text { could attain a final hydraulic } \\
\text { conductivity of } \approx 10^{-10} \mathrm{~m} / \mathrm{s} \\
\text { after CS grouting }\end{array}$ \\
\hline [13] & $\begin{array}{l}\text { Monterey silica sand No. } \\
0 / 30\left(\mathrm{D}_{50}=0.49 \mathrm{~mm}\right) \\
\text { and Trevino sandy loam } \\
\text { (52\% sand, } 42 \% \text { silt and } \\
6 \% \text { clay, by fraction) }\end{array}$ & $\begin{array}{l}\text { Falling head } \\
\text { permeability test }\end{array}$ & Soil and grout mixed in a cylinder mold & $\begin{array}{l}\mathrm{k} \text { ranged from } \approx 5 \times 10^{-9} \mathrm{~m} / \mathrm{s} \\
\quad \text { for } 5 \% \mathrm{CS} \text { content up to } \\
\approx 2 \times 10^{-11} \mathrm{~m} / \mathrm{s} \text { for } 27.5 \% \mathrm{CS} \\
\quad \text { content }(\mathrm{Monterey} \mathrm{sand}) ; \\
\mathrm{k} \text { ranged from } \approx 1.5 \times 10^{-9} \mathrm{~m} / \mathrm{s} \\
\quad \text { for } 5 \% \mathrm{CS} \text { content up to } \\
\approx 1.5 \times 10^{-10} \mathrm{~m} / \mathrm{s} \text { for } 27.5 \% \mathrm{CS} \\
\quad \text { content (Trevino loam) }\end{array}$ \\
\hline [48] & $\begin{array}{c}\text { Ticino silica sand } \\
\left(\mathrm{D}_{50}=0.6 \mathrm{~mm}, \mathrm{C}_{\mathrm{u}}=1.3\right. \\
\left.\mathrm{G}_{\mathrm{s}}=2.68\right)\end{array}$ & $\begin{array}{l}\text { Constant-flow } \\
\text { permeability test }\end{array}$ & Grout permeation & $\begin{array}{c}\text { k ranged from } 1.2 \times 10^{-9} \mathrm{~m} / \mathrm{s} \\
\text { to } 2.3 \times 10^{-9} \mathrm{~m} / \mathrm{s} \\
\text { for } 10 \% \text { CS content }\end{array}$ \\
\hline$[72]$ & $\begin{array}{l}\text { Leighton Buzzard sand } \\
\quad\left(\mathrm{D}_{50}=1.2 \mathrm{~mm}\right. \\
\left.\mathrm{C}_{\mathrm{u}}=1.26, \mathrm{G}_{\mathrm{s}}=2.65\right)\end{array}$ & Oedometer & $\begin{array}{l}\text { See Section 5.2.2 (Permeability estimated from } \\
\text { the consolidation times in oedometer tests) }\end{array}$ & $\begin{array}{l}\mathrm{k} \text { values } \approx 10^{-10} \mathrm{~m} / \mathrm{s} \text { for } \\
\text { grouted sand }\end{array}$ \\
\hline$[66]$ & $\begin{array}{c}\text { M31 quartz sand } \\
\left(D_{50}=0.31 \mathrm{~mm},\right. \\
\left.\mathrm{C}_{\mathrm{u}}=1.50, \mathrm{G}_{\mathrm{s}}=2.655\right)\end{array}$ & $\begin{array}{l}\text { Triaxial } \\
\text { permeability }\end{array}$ & $\begin{array}{c}\text { Grout permeation. } D_{\mathrm{r}}=40 \%, 100 / 50 \mathrm{~mm} \\
\text { height/diameter }\end{array}$ & $\begin{array}{l}\mathrm{K}=2.3 \times 10^{-9} \mathrm{~m} / \mathrm{s} \text { and } \\
\mathrm{k}=2.2 \times 10^{-11} \mathrm{~m} / \mathrm{s} \text { for } \mathrm{CS} \\
\text { contents } 6 \% \text { and } 10 \% \\
\quad \text { respectively }\end{array}$ \\
\hline$[14]$ & $\begin{array}{c}\text { Silica sand } \\
\left(\mathrm{D}_{50}=0.30 \mathrm{~mm},\right. \\
\left.\mathrm{C}_{\mathrm{u}}=1.6, \mathrm{G}_{\mathrm{s}}=2.65, \mathrm{SP}\right)\end{array}$ & Falling head & $\begin{array}{l}\text { Dry sand tamped in layers. } \mathrm{D}_{\mathrm{r}} \approx 50-64 \%, \\
100 / 50 \mathrm{~mm} \text { height } / \text { diameter, gel time } \approx 2 \mathrm{~h}, \\
\text { curing time } 1 \mathrm{~d} . \mathrm{CS} \text { content: } 2,5 \% \text {. } \\
\text { Specimens were first water-saturated and then } \\
\text { injected with grout under gravity; } \\
\text { k measurements before and after treatment }\end{array}$ & $\begin{array}{l}10^{4}\left(10^{5}\right) \text { fold } \mathrm{k} \text { reduction for } 2 \% \\
(5 \%) \text { CS grouted material }\end{array}$ \\
\hline
\end{tabular}




\section{In-Field Colloidal Silica Grouting for Liquefaction Mitigation}

Most of the earliest studies on field applications of colloidal silica grouting (e.g., [86,89,96]) aimed to prevent the flow of contaminants, while CS applications for liquefaction mitigation have been rarely discussed in the literature. Among these past studies, Noll et al. [96] described the treatment of a $5 \mathrm{~m}$ diameter zone $(\approx 3 \mathrm{~m}$ thick) with a $5 \%$ CS solution by means of a central injection well and radially disposed extraction wells, to demonstrate the ability of CS grout to prevent pollutants flow. Moridis et al. [17] injected a CS solution into a heterogeneous unsaturated gravel-sand-silt deposit by means of tube-à-manchette technology at depths of 3.0, 3.6 and $4.2 \mathrm{~m}$, with the aim of waste containment. A soil column $(\approx 3 \mathrm{~m}$ height $)$ uniformly grouted could be excavated after treatment.

Gallagher et al. [83] performed a field test on a $2 \mathrm{~m}$ thick sand layer $\left(D_{r}=40-45 \%\right.$ based on cone penetration test, CPT, results) located $\approx 6.5 \mathrm{~m}$ below the ground surface and treated with silica solution. CS grouting (injection by tube-a-manchette, two stage bottomup process) was followed by a blast-test to evaluate the level of improvement at the target site by comparing the pore pressure response and settlements measured in the treated area with those recorded in an adjacent untreated site. Eight injection wells, disposed radially on a $4.5 \mathrm{~m}$ radius zone, were used to pump the grout into the subsoil, and one extraction well was equipped with a submersible pump in the center of the improved area to direct the grout flow toward the inner of the circle. Low grouting pressures (75-150 kPa, $175 \mathrm{kPa}$ occasionally) were used for grout injection. After grouting, the injection wells were equipped with explosive charges at depth $(6.4 \mathrm{~m}$ and $8.5 \mathrm{~m}$ below the ground surface) to induce liquefaction. Based on the pore pressure analysis, the treated area liquefied (the calculated pore pressure ratio ranged from 0.93 to 1.04 immediately after blasting). However, no large deformations were recorded in the treated site, suggesting that the CS treatment had significantly improved the deformation resistance of the sand layer. Typical deformations connected to flow liquefaction (e.g., sand boils) were not observed. In an adjacent untreated test pile area, $0.5 \mathrm{~m}$ maximum settlements were recorded, while the maximum values in the treated site were $\approx 0.3 \mathrm{~m}$. The authors concluded that, even if liquefaction occurred in the treated layer according to the pore water pressure criterion, the minor settlements were clear indicators of the increased stiffness of the grouted site.

Rasouli et al. [84] presented a detailed report on the application of a controlled permeation CS grouting technique used to improve liquefiable areas at the Fukuoka Airport (Japan). A controlled curve drilling machine was developed and used to inject the stabilizing grout point-by-point by an injection hose inserted in a borehole. Two different areas of the Fukuoka Airport, named A and B in the study, needed to be improved. Zone A corresponded to the runway; therefore, to maintain its full operation during the treatment, vertical boring was not possible. The controlled curved drilling machine was used in zone A. Both zones A and B consisted of shallow liquefiable loose sand layers with 10.5\% (zone A) and 9.9\% (zone B) fines contents. A colloidal silica grout ( $8 \%$ silica content) was used for the improvement of both areas. Grouting pressures ranged between $300 \mathrm{kPa}$ and $500 \mathrm{kPa}$. The full operation of the runway in zone A was maintained while the point-bypoint improvement was successfully performed. Controlled permeation grouting was proven to be effective to deliver the silica grout in the vicinity of existing structures.

To date, the lack of data from field experience does not allow an a priori identification of the best injection technique for a given site. Furthermore, since not only the subsoil characteristics, but also the equipment and procedures can strongly influence the effectiveness of the subsoil stabilization, it would be of great advantage to produce test sections (e.g., before injection), allowing a proper evaluation of the effectiveness of the improvement treatment [36].

\section{Grouting Performance Evaluation}

In laboratory investigations, tracers can be easily used to evaluate the grout flow [51,82]; silica, and chloride ion ( $\mathrm{Cl}-$ ) concentration measurements can be adopted to evaluate the grouting performance [25,51,52]. Gallagher et al. [83], after in situ blasting, obtained several 
CPT and shear wave velocity profiles at different locations in the tested area: they found no significant increase in these profiles, concluding that those traditional field testing methods were less appropriate to measure the soil improvement. Starting from this consideration, Rasouli et al. [84] evaluated the grouting quality by three different approaches. They excavated several boreholes and extracted soil samples for analysis. Firstly, the grout injected was controlled by a methyl red indicator, a chemical that reacts to the $\mathrm{pH}$ of the water and that became red when in contact with CS. The methyl red indicator gave qualitative information on the improvement level. Then, they evaluated the silica content based on laboratory data and finally they performed unconsolidated undrained triaxial tests on undisturbed samples.

\section{Mechanism of Soil Improvement}

As shown in the previous sections, CS grouting improves the soil response under monotonic and cyclic loading, increasing the liquefaction resistance of cohesionless soil. However, the mechanism of improvement is still unclear: it has not yet been well clarified if the soil improvement entirely/truly depends on the grains' bonding. From the results of drained torsional shear tests, Kodaka et al. [61] stated that "the intercept of failure line occurs due to the cohesive properties of treated sand"; some studies agree with this interpretation (e.g., $[14,48])$; in some others, however, a curved, stress-dependent failure envelope was adopted for the treated soil $[70,71]$, assuming that the stabilized sand behaves substantially different from cemented or lightly cemented materials. According to Gallagher et al. [83], "the improvement mechanism of colloidal silica is bonding between the gel and the individual sand particles".

Bonding reduces the contractive tendency of loose soil, thus producing a delay in the development of extra pore pressure. Some experimental results, however, show that the extra pore water pressure build up is faster in treated than untreated sand subjected to cyclic loading [64,70]; in addition, the initial stiffness of treated soil is lower than for the untreated one under monotonic and cyclic loading [70,107], at least for cost-effective CS contents $[14,70,71,74]$. Furthermore, the bonding of grains justifies the increase in shear strength under monotonic loading, but not the behavior observed by some authors under 1D-normal compression. Additional complexity arises from the nature of the pore gel: being more compressible than water, it follows that "the significance of $r_{u}$ for CS sand does not represent the same physical meaning" as for untreated material [24]. The experimental results prove that the failure mechanism in treated sand is not intimately related to the extra pore water pressure accumulation, like for the untreated sand [64,70,83].

Concerning Monterey sand, Persoff et al. [13] stated that "any unconfined compressive strength results from the cementing effect of the grout [ ... ]. This suggests that the colloidal particles bond not only to each other, but also to the silica surface of the sand". Wong et al. [72], supported by microscopic analysis, stated that the silica particles filling the pores of grouted sand are responsible for the improved shear strength and stiffness under monotonic loading. The improved dilative behavior of treated soil agrees with this interpretation. Similarly, according to Salvatore et al. [49], the gel filling the pore space of grouted sand prevents the mobility of sand particles, thus improving its response under both static and cyclic loading conditions. Bonding would justify the increase in the shear modulus at small strain levels, and a decrease in the damping ratio due to artificial cementation should be expected. However, experimental results showed that the damping ratio of grouted sand was higher than for untreated material, ranging from negligible up to significant increase. It is probably due to the nature of the pore gel that the damping ratio is expected to increase, since the energy dissipation would be enhanced by the viscous nature of the gel. Moreover, the shear velocity of grouted material increased when measured in laboratory [78], but a remarkable increase in the shear wave velocity was not measured in field [83]. In conclusion, the mechanism of soil improvement has not been fully clarified yet. 


\section{Numerical Modeling of CS Grouted Materials}

All the aspects shown in the previous sections pose specific questions that need to be answered before dedicated constitutive models can be developed for CS grouted material. Specifically, the validity of the Effective Stress Principle for water-saturated soils is questionable when the treated soil is saturated with compressible gel. Moreover, due to the absence of a unique framework able to match all the different aspects of the behavior of grouted materials, dedicated constitutive models have not been developed yet. To date, only few studies discuss the adaption of pre-existing constitutive models to grouted soils. Kodaka et al. [60] modified an existing elasto-plastic constitutive model [113] for sand to account for the reduced excess pore pressure development due to the soil stabilization. Andrianopoulos et al. [85] adopted an existing bounding surface critical-state plasticity model for sands (NTUA-sands proposed by Andrianopoulos et al. [114]) without changing its mathematical formulation. The simulation of passively stabilized sand was undertaken by following two approaches, the first one being a recalibration of some of the model constants, to consider a stiffer and more dilative material. This approach essentially reflects the modifications induced by grouting to the soil skeleton. Following the second procedure, the authors assumed the same model parameters for both treated and untreated sand, while the more seemingly compressible pore gel was modeled by reducing the bulk modulus of pore fluid in coupled analysis, to simulate the slower pore pressure build-up in treated sand. Element tests on stabilized sand were successfully simulated, while the model was not fully capable of simulating the system response in a boundary value problem (i.e., a centrifuge test). By way of example, Figure 15 shows the effects of increasing the plastic modulus constant $h_{0}$ of the NTUA-sand model $\left(h_{0}\right.$ is a positive scalar multiplier of the plastic modulus of the model) on the predicted surface settlements over time and compares numerical simulation with pertinent recorded data from a centrifuge test on stabilized sand (data from [25]).

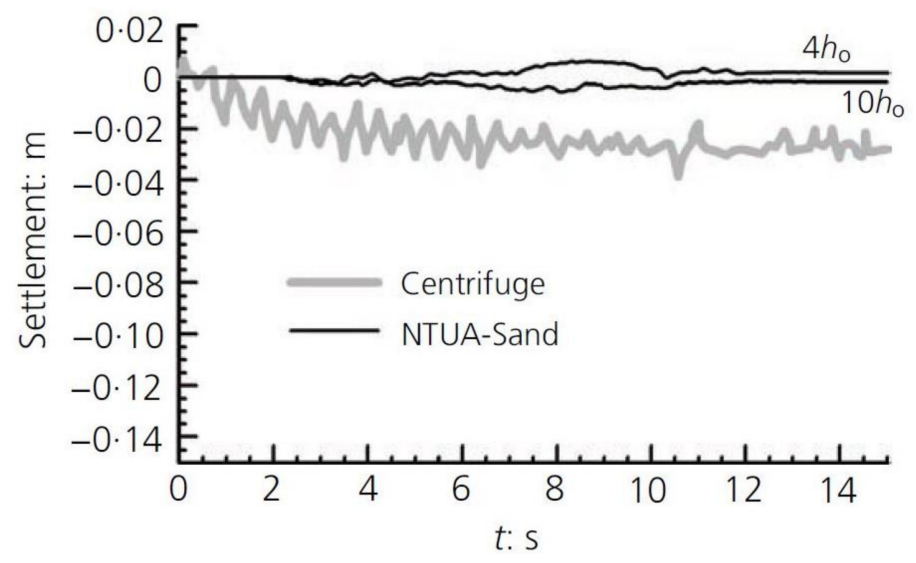

Figure 15. Comparison of surface settlements from numerical simulation and centrifuge testing on CS-treated sand [85].

The authors stated that the most promising approach to simulate boundary value problems consisted in the decrease in the pore fluid bulk modulus. This phenomenological approach used to simulate the effects of CS grouting was also used in Papadimitriou et al. [115], to numerically investigate the effectiveness of this grouting method to mitigate the liquefaction-induced buried pipe uplift.

\section{Summary and Conclusions}

The current state of knowledge on the main aspects concerning the soil treatment by colloidal silica grouting, a non-standard soil stabilization technique, was presented and discussed in this paper. The literature studies were critically reviewed analyzing benefits and drawbacks of this technique, with particular emphasis on CS grouting as a liquefaction mitigation technique, without neglecting other possible grouting applications. 
While the behavior of small-sized soil elements has been widely described in the literature, research studies on physical and on-site models are still limited. The main conclusions which emerged from a critical review of the existing studies can be summarized as follows:

- CS grout can be successfully transported through porous media; however, the effects related to grout viscosity increase over time and grout sinking need to be considered in design;

- $\quad$ CS grouting improves the liquefaction resistance of liquefiable soil;

- CS grouting enhances the soil strength under monotonic loading conditions;

- The strength of the treated material increases with the increase in both CS content and gel aging;

- The treated soil shows enhanced dilative behavior under monotonic loading conditions;

- The mechanism of soil improvement has not been fully clarified yet;

- The effects of CS grouting at low-medium strain levels have not been fully clarified yet;

- The compressibility of the treated material seems to be greater than that of the untreated one, at least for the CS contents that would be cost-effective for liquefaction mitigation;

- The CS treatment produces a significant decrease in soil hydraulic conductivity;

- Field experiences of CS grouting demonstrated the feasibility of this improvement method;

- Appropriate constitutive models able to simulate the behavior of the CS-treated material have not been developed yet;

In conclusion, from the current state of knowledge on the subject, it is clear that the behavior of soil treated with CS grout is very complex. To shed light on controversial or not yet fully discussed aspects, future research on colloidal silica grouting should further investigate the following aspects:

- The effects of CS grout on soil compressibility;

- The effects of CS grout on damping ratio;

- The sinking phenomenon in the grout delivery process;

- The development of adequate constitutive laws to describe the behavior of the stabilized soil;

Finally, before the application of the CS grouting stabilization technique in engineering practice, the use of test sections is strongly recommended, for both identifying the most appropriate site-specific design parameters and evaluating the performance and effectiveness of the CS treatment.

Author Contributions: Conceptualization, G.C. and C.M.; investigation, G.C.; resources, G.C.; original draft preparation, G.C.; writing-review and editing, G.C., G.V. and C.M.; supervision, G.V. and C.M.; project administration, C.M.; funding acquisition, C.M. All authors have read and agreed to the published version of the manuscript.

Funding: This study was partially supported by DPC-ReLUIS Research Project 2019-2021.

Conflicts of Interest: The authors declare that they have no conflict of interest associated with this publication and no financial support has been given to influence the outcome of this work.

\section{References}

1. Hausmann, M.R. Engineering Principles of Ground Modification; McGraw-Hill: New York, NY, USA, 1990; ISBN 9780070272798.

2. Karol, R.H. Chemical Grouting and Soil Stabilization, Revised and Expanded; CRC Press: Boca Raton, FL, USA, 2003.

3. Han, J. Principles and Practice of Ground Improvement; John Wiley \& Sons: Hoboken, NJ, USA, 2005.

4. DeJong, J.T.; Mortensen, B.M.; Martinez, B.C.; Nelson, D.C. Bio-mediated soil improvement. Ecol. Eng. 2010, 36, 197-210. [CrossRef]

5. European Commission. Commission Recommendation of 18 October 2011 on the Definition of Nanomaterial. Off. J. Eur. Union 2011,38-40; 2011/696/EU. Available online: https:/ / eur-lex.europa.eu/LexUriServ /LexUriServ.do?uri=OJ:L:2011:275:0038:0040: EN:PDF (accessed on 20 November 2021).

6. Huang, Y.; Wang, L. Experimental studies on nanomaterials for soil improvement: A review. Environ. Earth Sci. 2016, 75, 496-510. [CrossRef] 
7. Ghasabkolaei, N.; Janalizadeh Choobbasti, A.; Roshan, N.; Ghasemi, S.E. Geotechnical properties of the soils modified with nanomaterials: A comprehensive review. Arch. Civ. Mech. Eng. 2017, 17, 639-650. [CrossRef]

8. Krishnan, J.; Shukla, S. The behaviour of soil stabilised with nanoparticles: An extensive review of the present status and its applications. Arab. J. Geosci. 2019, 12, 436. [CrossRef]

9. Liu, G.; Zhang, C.; Zhao, M.; Guo, W.; Luo, Q. Comparison of nanomaterials with other unconventional materials used as additives for soil improvement in the context of sustainable development: A review. Nanomaterials 2021, 11, 15. [CrossRef] [PubMed]

10. Kananizadeh, N.; Ebadi, T.; Ehsan, S.; Rizi, M.; Khoshniat, S.A. Behavior of nanoclay as an additive in order to reduce Kahrizak landfill clay permeability. In Proceedings of the 2nd International Conference on Environmental Science and Technology, Singapore, 26-28 February 2011; pp. 26-28.

11. Nikookar, M.; Bahari, M.; Nikookar, H.; Arabani, M. The Strength Characteristics of Silty Soil Stabilized Using Nano-Clay. In Proceedings of the 7th Symposium on Advances in Science \& Technology (7thSASTech), Bandar-Abbas, Iran, 7-8 March 2013.

12. Ng, C.W.W.; Coo, J.L. Hydraulic conductivity of clay mixed with nanomaterials. Can. Geotech. J. 2015, 52, 808-811. [CrossRef]

13. Persoff, P.; Apps, J.; Moridis, G.; Whang, J.M. Effect of dilution and contaminants on sand grouted with colloidal silica. J. Geotech. Geoenv. Eng. 1999, 125, 461-469. [CrossRef]

14. Ciardi, G.; Bardotti, R.; Vannucchi, G.; Madiai, C. Effects of high-diluted colloidal silica grouting on the behaviour of a liquefiable sand. Geotech. Res. 2020, 7, 193-208. [CrossRef]

15. Rabbani, M.M.; Ahmed, I.; Park, S.J. Application of nanotechnology to remediate contaminated soils. In Environmental Remediation Technologies for Metal-Contaminated Soils; Hasegawa, H., Rahman, I., Rahman, M., Eds.; Springer: Tokyo, Japan, 2016; pp. 219-229, ISBN 9784431557593.

16. Persoff, P.; Moridis, G.J.; Apps, J.; Pruess, K.; Muller, S.J. Designing injectable colloidal silica barriers for waste isolation at the Hanford site. In Proceedings of the 33rd Hanford Symposium on Health and Environment-In Situ Remediation: Scientific Basis for Current and Future Technologies, Part 1, Pasco, WA, USA, 7-11 November 1994; pp. 87-101.

17. Moridis, G.J.; Apps, J.; Persoff, P.; Myer, L.; Muller, S.; Yen, P.; Pruess, K. A field test of a waste containment technology using a new generation of injectable barrier liquids. In Proceedings of the Spectrum 96, Seattle, WA, USA, 18-23 August 1996.

18. Funehag, J.; Gustafson, G. Design of grouting with silica sol in hard rock-New design criteria tested in the field, Part II. Tunn. Undergr. Space Technol. 2008, 23, 9-17. [CrossRef]

19. Butrón, C.; Gustafson, G.; Fransson, Å.; Funehag, J. Drip sealing of tunnels in hard rock: A new concept for the design and evaluation of permeation grouting. Tunn. Undergr. Space Technol. 2010, 25, 114-121. [CrossRef]

20. El Mohtar, C.S.; Bobet, A.; Santagata, M.C.; Drnevich, V.P.; Johnston, C.T. Liquefaction mitigation using bentonite suspensions. J. Geotech. Geoenv. Eng. 2013, 139, 1369-1380. [CrossRef]

21. Ochoa-Cornejo, F.; Bobet, A.; Johnston, C.T.; Santagata, M.; Sinfield, J.V. Cyclic behavior and pore pressure generation in sands with laponite, a super-plastic nanoparticle. Soil Dyn. Earthq. Eng. 2016, 88, 265-279. [CrossRef]

22. Huang, Y.; Wen, Z.; Wang, L.; Zhu, C. Centrifuge testing of liquefaction mitigation effectiveness on sand foundations treated with nanoparticles. Eng. Geol. 2019, 249, 249-256. [CrossRef]

23. Gallagher, P.M.; Mitchell, J.K. Influence of colloidal silica grout on liquefaction potential and cyclic undrained behavior of loose sand. Soil Dyn. Earthq. Eng. 2002, 22, 1017-1026. [CrossRef]

24. Conlee, C.T.; Gallagher, P.M.; Boulanger, R.W.; Kamai, R. Centrifuge modeling for liquefaction mitigation using colloidal silica stabilizer. J. Geotech. Geoenv. Eng. 2012, 138, 1334-1345. [CrossRef]

25. Gallagher, P.M.; Pamuk, A.; Abdoun, T. Stabilization of liquefiable soils using colloidal silica grout. J. Mater. Civ. Eng. 2007, 19, 33-40. [CrossRef]

26. Huang, Y.; Wen, Z. Recent developments of soil improvement methods for seismic liquefaction mitigation. Nat. Hazards 2015, 76, 1927-1938. [CrossRef]

27. Krishnan, J.; Shukla, S. Seismic Mitigation Liquefaction-An Extensive Study on New Concepts; Lecture Notes in Civil Engineering Book Series; Springer: Singapore, 2021; Volume 117, pp. 369-379.

28. DeJong, J.T.; Fritzges, M.B.; Nüsslein, K. Microbially induced cementation to control sand response to undrained shear. J. Geotech. Geoenv. Eng. 2006, 132, 1381-1392. [CrossRef]

29. Montoya, B.M.; DeJong, J.T.; Boulanger, R.W. Dynamic response of liquefiable sand improved by microbial-induced calcite precipitation. Géotechnique 2013, 63, 302-312. [CrossRef]

30. Xiao, P.; Liu, H.; Stuedlein, A.W.; Evans, T.M.; Xiao, Y. Effect of relative density and biocementation on cyclic response of calcareous sand. Can. Geotech. J. 2019, 56, 1849-1862. [CrossRef]

31. Yegian, M.K.; Eseller-Bayat, E.; Alshawabkeh, A.; Ali, S. Induced-Partial saturation for liquefaction mitigation: Experimental investigation. J. Geotech. Geoenv. Eng. 2007, 133, 372-380. [CrossRef]

32. Okamura, M.; Takebayashi, M.; Nishida, K.; Fujii, N.; Jinguji, M.; Imasato, T.; Yasuhara, H.; Nakagawa, E. In-Situ desaturation test by air injection and its evaluation through field monitoring and multiphase flow simulation. J. Geotech. Geoenv. Eng. 2011, 137, 643-652. [CrossRef]

33. He, J.; Chu, J.; Ivanov, V. Mitigation of liquefaction of saturated sand using biogas. Géotechnique 2013, 63, 267-275. [CrossRef]

34. Zornberg, J.G.; Cabral, A.R.; Viratjandr, C. Behaviour of tire shred sand mixtures. Can. Geotech. J. 2004, 41, 227-241. [CrossRef] 
35. Mashiri, M.S.; Vinod, J.S.; Sheikh, M.N. Liquefaction potential and dynamic properties of Sand-Tyre Chip (STCh) mixtures. Geotech. Test. J. 2016, 39, 69-79. [CrossRef]

36. Kramer, S.L. Geotechnical Earthquake Engineering; Prentice Hall: New York, NY, USA, 1996.

37. Towhata, I.; Kabashima, Y. Mitigation of seismically-induced deformation of loose sandy foundation by uniform permeation grouting. In Proceedings of the Earthquake Geotechnical Engineering Satellite Conference, XVth International Conference on Soil Mechanics and Geotechnical Engineering, Istanbul, Turkey, 27-31 August 2001; pp. 313-318.

38. Liao, H.J.; Huang, C.C.; Chao, B.S. Liquefaction Resistance of a Colloid Silica Grouted Sand. In Proceedings of the 3rd International Conference on Grouting and Ground Treatment, New Orleans, LA, USA, 10-12 February 2003; pp. 1305-1313.

39. Díaz-Rodríguez, J.A.; Antonio-Izarraras, V.M. Mitigation of liquefaction risk using colloidal silica stabilizer. In Proceedings of the 13th World Conference on Earthquake Engineering, Vancouver, BC, Canada, 1-6 August 2004.

40. Zhao, M.; Liu, G.; Zhang, C.; Guo, W.; Luo, Q. State-of-the-Art of colloidal silica-based soil liquefaction mitigation: An emerging technique for ground improvement. Appl. Sci. 2020, 10, 15. [CrossRef]

41. Krishnan, J.; Shukla, S. The utilisation of colloidal silica grout in soil stabilisation and liquefaction mitigation: A state of the art review. Geotech. Geol. Eng. 2021, 39, 2681-2706. [CrossRef]

42. Seright, R.S. Reduction of gas and water permeabilities using gels. SPE Prod. Facil. 1995, 10, 103-108. [CrossRef]

43. Gallagher, P.M. Passive Site Remediation for Mitigation of Liquefaction Risk; Virginia Polytechnic Institute and State University: Blacksburg, VA, USA, 2000.

44. Iler, R.K. The Chemistry of Silica: Solubility, Polymerization, Colloid and Surface Properties and Biochemistry of Silica; John Wiley and Sons Inc.: New York, NY, USA, 1979.

45. Bergna, H.E.; Roberts, W.O. (Eds.) Colloidal Silica: Fundamentals and Applications; CRC Press: Boca Raton, FL, USA, 2005.

46. Agapoulaki, G.I.; Papadimitriou, A.G. Rheological properties of colloidal silica grout for passive stabilization against liquefaction. J. Mater. Civ. Eng. 2018, 30, 4018251. [CrossRef]

47. Díaz-Rodríguez, J.A.; Antonio-Izarraras, V.M.; Bandini, P.; López-Molina, J.A. Cyclic strength of a natural liquefiable sand stabilized with colloidal silica grout. Can. Geotech. J. 2008, 45, 1345-1355. [CrossRef]

48. Porcino, D.; Marcianò, V.; Granata, R. Static and dynamic properties of a lightly cemented silicate-grouted sand. Can. Geotech. J. 2012, 49, 1117-1133. [CrossRef]

49. Salvatore, E.; Modoni, G.; Mascolo, M.C.; Grassi, D.; Spagnoli, G. Experimental evidence of the effectiveness and applicability of colloidal nanosilica grouting for liquefaction mitigation. J. Geotech. Geoenv. Eng. 2020, 146, 04020108. [CrossRef]

50. Krishnan, J.; Sharma, P.; Shukla, S.; Pancholi, V.; Dwivedi, V.K. Cyclic behaviour and durability analysis of sand grouted with optimum colloidal silica content. Arab. J. Sci. Eng. 2020, 45, 8129-8144. [CrossRef]

51. Gallagher, P.M.; Finsterle, S. Physical and numerical model of colloidal silica injection for passive site stabilization. Vadose Zo. J. 2004, 3, 917-925. [CrossRef]

52. Gallagher, P.M.; Lin, Y. Colloidal silica transport through liquefiable porous media. J. Geotech. Geoenv. Eng. 2009, 135, 1702-1712 [CrossRef]

53. Gallagher, P.M.; Koch, A.J.; Pamuk, A.; Abdoun, T.H.; Mitchell, J.K. Centrifuge Model of Passive Site Remediation. In Proceedings of the 7th U.S. National Conference on Earthquake Engineering (7NCEE), Boston, MA, USA, 21-25 July 2002.

54. Gallagher, P.M.; Koch, A.J. Model Testing of Passive Site Stabilization: A New Grouting Technique. In Grouting and Ground Treatment; ASCE: Reston, VA, USA, 2003; pp. 1478-1489.

55. Axelsson, M. Mechanical tests on a new non-cementitious grout, silica sol: A laboratory study of the material characteristics. Tunn. Undergr. Space Technol. 2006, 21, 554-560. [CrossRef]

56. Butrón, C.; Axelsson, M.; Gustafson, G. Silica sol for rock grouting: Laboratory testing of strength, fracture behaviour and hydraulic conductivity. Tunn. Undergr. Space Technol. 2009, 24, 603-607. [CrossRef]

57. Agapoulaki, G.I.; Papadimitriou, A.G. Rheological properties of colloidal silica as a means for designing passive stabilization of liquefiable soils. In Proceedings of the 16th European Conference on Soil Mechanics and Geotechnical Engineering, Edinburgh, UK, 13-17 September 2015; pp. 2331-2336.

58. Sögaard, C.; Funehag, J.; Abbas, Z. Silica sol as grouting material: A physio-chemical analysis. Nano Converg. 2018, 5, 6. [CrossRef]

59. Cao, X.J.; Cummins, H.Z.; Morris, J.F. Structural and rheological evolution of silica nanoparticle gels. Soft Matter 2010, 6, 5425-5433. [CrossRef]

60. Kodaka, T.; Oka, F.; Ohno, Y.; Takyu, T.; Yamasaki, N. Modeling of cyclic deformation and strength characteristics of silica treated sand. In Geomechanics: Testing, Modeling and Simulation; ASCE: Reston, VA, USA, 2005; pp. 205-216.

61. Kodaka, T.; Ohno, Y.; Takyu, T. Cyclic shear characteristics of treated sand with colloidal silica grout. In Proceedings of the 16th International Conference on Soil Mechanics and Geotechnical Engineering, Osaka, Japan, 12-16 September 2005; pp. 401-404.

62. Pamuk, A.; Gallagher, P.M.; Zimmie, T.F. Remediation of piled foundations against lateral spreading by passive site stabilization technique. Soil Dyn. Earthq. Eng. 2007, 27, 864-874. [CrossRef]

63. Mollamahmutoglu, M.; Yilmaz, Y. Pre- and post-cyclic loading strength of silica-grouted sand. Proc. Inst. Civ. Eng. Geotech. Eng. 2010, 163, 343-348. [CrossRef]

64. Porcino, D.; Marcianò, V.; Granata, R. Undrained cyclic response of a silicate-grouted sand for liquefaction mitigation purposes. Geomech. Geoengin. 2011, 6, 155-170. [CrossRef] 
65. Vranna, A.; Tika, T. Undrained Monotonic and Cyclic Behaviour of a Silty Sand Stabilized with Colloidal Silica. In Proceedings of the 6th International Conference on Earthquake Geotechnical Engineering, Christchurch, New Zealand, 1-4 November 2015.

66. Vranna, A.; Tika, T. Laboratory improvement of liquefiable sand via colloidal silica and weak cementation. Proc. Inst. Civ. Eng. Gr. Improv. 2019, 174, 240-251. [CrossRef]

67. Ciardi, G.; Bardotti, R.; Vannucchi, G.; Madiai, C. Effects of high-diluted colloidal silica grout on the mechanical behavior of a liquefiable sand. In Proceedings of the 7th International Conference on Earthquake Geotechnical Engineering, Roma, Italy, 17-20 June 2019; pp. 1820-1827.

68. Vranna, A.; Tika, T.; Papadimitriou, A. Laboratory investigation into the monotonic and cyclic behaviour of a clean sand stabilised with colloidal silica. Géotechnique 2020. (ahead of print). [CrossRef]

69. Vranna, A.; Tika, T. The mechanical response of a silty sand stabilized with colloidal silica. Geotechnics 2021, 1, 243-259. [CrossRef]

70. Pavlopoulou, E.M.; Georgiannou, V.N. Effect of colloidal silica aqueous gel on the monotonic and cyclic response of sands. J. Geotech. Geoenv. Eng. 2021, 147, 04021122. [CrossRef]

71. Georgiannou, V.N.; Pavlopoulou, E.M.; Bikos, Z. Mechanical behaviour of sand stabilised with colloidal silica. Proc. Inst. Civ. Eng. Geotech. Res. 2017, 4, 1-11. [CrossRef]

72. Wong, C.; Pedrotti, M.; El Mountassir, G.; Lunn, R.J. A study on the mechanical interaction between soil and colloidal silica gel for ground improvement. Eng. Geol. 2018, 243, 84-100. [CrossRef]

73. Nouri Delavar, I.; Noorzad, R. Drained shear strength parameters of silty sand grouted by colloidal silica. Int. J. Geotech. Eng. 2020, 14, 1-8. [CrossRef]

74. Triantafyllos, P.K.; Georgiannou, V.N.; Pavlopoulou, E.-M.; Dafalias, Y.F. Strength and dilatancy of sand before and after stabilisation with colloidal-silica gel. Géotechnique 2021. (ahead of print). [CrossRef]

75. Krishnan, J.; Sharma, P.; Shukla, S. Experimental investigations on the mechanical properties of sand stabilized with colloidal silica. Iran. J. Sci. Technol. Trans. Civ. Eng. 2021, 45, 1737-1758. [CrossRef]

76. Ghadr, S.; Assadi-Langroudi, A.; Hung, C.; O'Kelly, B.C.; Bahadori, H.; Ghodsi, T. Stabilization of sand with colloidal nano-silica hydrosols. Appl. Sci. 2020, 10, 5192. [CrossRef]

77. Spencer, L.M.; Rix, G.J.; Gallagher, P.M. Dynamic properties of colloidal silica gel and sand mixtures. In Proceedings of the 4th International Conference on Earthquake Geotechnical Engineering, Thessaloniki, Greece, 25-28 June 2007.

78. Spencer, L.; Rix, G.J.; Gallagher, P.M. Colloidal silica gel and sand mixture dynamic properties. In Proceedings of the Geotechnical Earthquake Engineering and Soil Dynamics Congress IV, Sacramento, CA, USA, 18-22 May 2008.

79. Batilas, A.; Pantazopoulos, I.; Athanasopoulos, G. Effects of colloidal silica grouting on the dynamic properties of sandy soils. In Proceedings of the 16th European Conference on Earthquake Engineering, Thessaloniki, Greece, 18-21 June 2018.

80. Gallagher, P.M.; Lin, Y. Column Testing to determine Colloidal Silica Transport Mechanisms. In Proceedings of the Geo-Frontiers Congress 2005, Austin, TX, USA, 24-26 January 2005.

81. Hamderi, M.; Gallagher, P.M. Pilot-Scale modeling of colloidal silica delivery to liquefiable sands. Soils Found. 2015, 55, 143-153. [CrossRef]

82. Bolisetti, T.; Reitsma, S.; Balachandar, R. Experimental investigations of colloidal silica grouting in porous media. J. Geotech. Geoenv. Eng. 2009, 135, 697-700. [CrossRef]

83. Gallagher, P.M.; Conlee, C.T.; Rollins, K.M. Full-Scale field testing of colloidal silica grouting for mitigation of liquefaction risk. J. Geotech. Geoenv. Eng. 2007, 133, 186-196. [CrossRef]

84. Rasouli, R.; Hayashi, K.; Zen, K. Controlled permeation grouting method for mitigation of liquefaction. J. Geotech. Geoenv. Eng. 2016, 142, 04016052. [CrossRef]

85. Andrianopoulos, K.I.; Agapoulaki, G.I.; Papadimitriou, A.G. Simulation of seismic response of passively stabilised sand. Geotech Res. 2016, 3, 40-53. [CrossRef]

86. Moridis, G.J.; Persoff, P.; Apps, J.A.; Myer, L.; Pruess, K.; Yen, P. A field test of permeation grouting in heterogeneous soils using a new generation of barrier liquids. In Proceedings of the Environmental Remediation' 95 Conference, Denver, CO, USA, 13-18 August 1995.

87. Whang, J.M. Chemical-Based barrier materials. In Assessment of Barrier Containment Technologies for Environmental Remediation Applications; Rumer, R.R., Mitchell, J.K., Eds.; National Technical Information Service: Springfield, VA, USA, 1995 ; pp. $211-247$.

88. Jurinak, J.J.; Summers, L.E. Oilfield applications of colloidal silica gel. SPE Prod. Eng. 1991, 6, 406-412. [CrossRef]

89. Noll, M.R.; Bartlett, C.; Dochat, T.M. In Situ permeability reduction and chemical fixation using colloidal silica. In Proceedings of the Sixth National Outdoor Action Conference on Aquifer Restoration, Ground Water Monitoring, and Geophysical Method, National Ground Water Association, Las Vegas, NV, USA, 11-13 May 1992; pp. 443-457.

90. Durmusoglu, E.; Yavuz Corapcioglu, M. Experimental study of horizontal barrier formation by colloidal silica. J. Environ. Eng. 2000, 126, 833-841. [CrossRef]

91. Towhata, I. Geotechnical Earthquake Engineering; Wei, W., Borja, R.I., Eds.; Springer: Berlin/Heidelberg, Germany, 2008.

92. Higgo, J.J.W.; Williams, G.M.; Harrison, I.; Warwick, P.; Gardiner, M.P.; Longworth, G. Colloid transport in a glacial sand aquifer. Laboratory and field studies. Colloids Surfaces A Physicochem. Eng. Asp. 1993, 73, 179-200. [CrossRef]

93. Saiers, J.E.; Hornberger, G.M.; Harvey, C. Colloidal silica transport through structured, heterogeneous porous media. J. Hydrol. 1994, 163, 271-288. [CrossRef] 
94. Johnson, P.R.; Sun, N.; Elimelech, M. Colloid transport in geochemically heterogeneous porous media: Modeling and measurements. Environ. Sci. Technol. 1996, 30, 3284-3293. [CrossRef]

95. Fujita, Y.; Kobayashi, M. Transport of colloidal silica in unsaturated sand: Effect of charging properties of sand and silica particles. Chemosphere 2016, 154, 179-186. [CrossRef]

96. Noll, M.R.; Epps, D.E.; Bartlett, C.L.; Chen, P.J. Pilot field application of a colloidal silica gel technology for in situ hot spot stabilization and horizontal grouting. In Proceedings of the 7th National Outdoor Action Conference, National Ground Water Association, Las Vegas, NV, USA, 25-27 May 1993; pp. 207-219.

97. Hamderi, M.; Gallagher, P.M. An optimization study on the delivery distance of colloidal silica. Sci. Res. Essays 2013, 8, 1314-1323.

98. Weggel, J.R.; Gallagher, P.; Lin, Y. Analytical model for transport of dilute colloidal silica dispersions through porous media. J. Geotech. Geoenv. Eng. 2018, 144, 4018082. [CrossRef]

99. Agapoulaki, G.I.; Papadimitriou, A.G.; Kandris, K.; Pantazidou, M. Permeation potential of colloidal silica for passive stabilization of liquefiable soils. In Proceedings of the XVI ECSMGE Geotechnical Engineering for Infrastructure and Development, Edinburgh, UK, 13-17 September 2015; pp. 2201-2206.

100. Weggel, J.R.; Gallagher, P.; Lin, Y. Closure to “Analytical Model for Transport of Dilute Colloidal Silica Dispersions through Porous Media" by J. Richard Weggel, Patricia Gallagher, and Yuanzhi Lin. J. Geotech. Geoenv. Eng. 2019, 145, 07019014. [CrossRef]

101. Lin, Y. Colloidal Silica Transport Mechanisms for Passive Site Stabilization of Liquefiable Soils; Drexel University: Philadelphia, PA, USA, 2006.

102. Ishihara, K. Soil Behaviour in Earthquake Geotechnics; Clarendon Press: Oxford, UK, 1996.

103. Castro, G. Liquefaction and cyclic mobility of saturated sands. J. Geotech. Eng. Div. 1975, 101, 551-569. [CrossRef]

104. Castro, G.; Poulos, S.J. Factors affecting liquefaction and cyclic mobility. J. Geotech. Eng. Div. 1977, 103, 501-516. [CrossRef]

105. Castro, G.; Enos, J.L.; France, J.W.; Poulos, S.J. Liquefaction induced by cyclic loading. NASA STI/Recon Tech. Rep. N 1982, 83, 13308.

106. Japanese Geotechnical Society. Remedial Measures against Soil Liquefaction: From Investigation and Design to Implementation; Japanese Geotechnical Society, Ed.; Balkema: Rotterdam, NL, USA, 1998.

107. Ciardi, G. Effects of High-Diluted Colloidal Silica Mixtures on the Mechanical Behavior of Potentially Liquefiable Sand; University of Florence/Technische Universität Braunschweig: Florence, Italy, 2019.

108. Taboada, V. Centrifuge Modeling of Earthquake-Induced Lateral Spreading Using a Laminar Box. Ph.D. Thesis, Department of Civil Engineering, Rensselaer Polytechnic Institute, Troy, NY, USA, 1995.

109. Pedrotti, M. (University of Strathclyde, Glasgow, UK). Personal communication, 2018.

110. Sharma, P.; Krishnan, J.; Shruti, S. A Feasibility Study of Colloidal Silica as Stabilizing Material for Passive Site Remediation. In Advances in Civil Engineering; Springer: Singapore, 2021; Volume 83, pp. 333-347.

111. Moradi, G.; Seyedi, S. Effect of sampling method on strength of stabilized silty sands with colloidal nano silica. J. Civ. Eng. Res. 2015, 5, 129-135.

112. Yonekura, R.; Miwa, M. Fundamental properties of sodium silicate based grout. In Proceedings of the Eleventh South East Asian Geotechnical Conference, Singapore, 4-8 May 1993; pp. 439-444.

113. Oka, F.; Yashima, A.; Tateishi, A.; Taguchi, Y.; Yamashita, A. A cyclic elasto-plastic constitutive model for sand considering a plastic-strain dependence of the shear modulus. Géotechnique 1999, 49, 661-680. [CrossRef]

114. Andrianopoulos, K.I.; Papadimitriou, A.G.; Bouckovalas, G.D. Bounding surface plasticity model for the seismic liquefaction analysis of geostructures. Soil Dyn. Earthq. Eng. 2010, 30, 895-911. [CrossRef]

115. Papadimitriou, A.G.; Limnaiou, T.; Kympouri, M. Mitigation of liquefaction-induced pipeline uplift using passive stabilization. In Proceedings of the 7th International Conference on Earthquake Geotechnical Engineering, Roma, Italy, 17-20 June 2019; pp. $4327-4334$. 